\title{
Key factors identified by proteomic analysis in maize (Zea mays L.) seedlings' response to long-term exposure to different phosphate levels
}

\author{
Yanling Sun ${ }^{1 *}$, Chunhua Mu ${ }^{1}$ and Xia Liu ${ }^{1,2^{*}}$
}

\begin{abstract}
Background: Maize seedlings are constantly exposed to inorganic phosphate (Pi)-limited environments. To understand how maize cope with low Pi (LP) and high Pi (HP) conditions, physiological and global proteomic analysis of QXN233 genotype were performed under the long-term Pi starvation and supplementation.

Methods: We investigated the physiological response of QXN233 genotype to LP and HP conditions and detected the changes in ion fluxes by non-invasive micro-test technology and gene expression by quantitative real-time polymerase chain reaction. QXN233 was further assessed using vermiculite assay, and then proteins were isolated and identified by nano-liquid chromatography-mass spectrometry.

Results: A negative relationship was observed between $\mathrm{Na}^{+}$and $\mathrm{Pi}$, and $\mathrm{Na}^{+}$efflux was enhanced under $\mathrm{HP}$ condition. Furthermore, a total of 681 and 1374 were identified in the leaves and roots, respectively, which were mostly involved in metabolism, ion transport, and stress response. Importantly, several key Pi transporters were identified for breeding potential. Several ion transporters demonstrated an elaborate interplay between Pi and other ions, together contributing to the growth of QXN233 seedlings.
\end{abstract}

Conclusion: The results from this study provide insights into the response of maize seedlings to long-term Pi exposure.

Keywords: Proteomics, Maize seedlings, Low-pi tolerance, Pi transporter

\section{Background}

Phosphorus $(\mathrm{P})$ is an essential macronutrient required for normal plant growth and reproduction. P is involved in various metabolism and biological processes, including nucleic acid and protein synthesis, membrane integrity, photosynthesis, respiration, energy metabolism, hormone regulation, stress tolerance, and disease resistance $[1,2]$. However, approximately $50 \%$ of global agricultural soils suffers from inorganic phosphate $(\mathrm{Pi})$ deficiency $[3,4]$. The reason is because plants absorb $\mathrm{P}$ in the available form of $\mathrm{Pi}$, which is usually limited in soils due to its immobility and high binding state $[5,6]$.

\footnotetext{
* Correspondence: sylsk046@163.com; snakepy@126.com

${ }^{1}$ Maize Research Institute, Shandong Academy of Agricultural Sciences/ National Engineering Laboratory of Wheat and Maize/Key Laboratory of Biology and Genetic Improvement of Maize in Northern Yellow-huai River Plain, Ministry of Agriculture, Jinan 250100, China

Full list of author information is available at the end of the article
}

Nevertheless, plants use various strategies to adapt to low-Pi (LP) stress, including using free Pi from vacuolar storages [7], deriving organic $\mathrm{P}$ from the breakdown of phospholipids, redistributing Pi from old to young tissues, modifying of the root system to increase Pi uptake, obtaining Pi from arbuscular mycorrhizal association [8], and secreting of organic acids and phosphatases to release available Pi from the soil [9-11].

Under Pi deficiency, plants were chlorotic, markedly small and not-well development, presenting necrosis toward the tips of the oldest leaves. Conversely, plants become high and grow up strongly under Pi-sufficient condition [12, 13]. Until now, it has been known that various proteins with $\mathrm{Pi}$ transport activity include PHT (phosphate receptor) proteins (involved in Pi uptake from soil and Pi translocation) and the SPX (SYG1, Pho81 and XPR1) domain phosphate transporters [14-18], such as

(c) The Author(s). 2018 Open Access This article is distributed under the terms of the Creative Commons Attribution 4.0 International License (http://creativecommons.org/licenses/by/4.0/), which permits unrestricted use, distribution, and 
SPX-EXS (ERD1, XPR1, and SYG1) subfamily PHO1 and its homologs (involved in $\mathrm{Pi}$ transport from roots to shoots) [19, 20], and the SPX-MFS (major facilitator superfamily) subfamily including VPT1 (vacuolar Pi transporter 1, also named PHT5;1) [21] and OsPHO1;2 (involved in vacuolar Pi transport) [22]. The PHT1 family, which are localized on the plasma membranes, related with highly efficient $\mathrm{Pi}$ acquisition from soils, has received considerable attention $[6,10,23,24]$. Moreover, the PHT2, PHT3, PHT4, and PHT5 family members, which are localized to chloroplasts, mitochondria, Golgi, and vacuole, respectively, and mediated $\mathrm{Pi}$ transport across these organelles $[25,26]$. In maize (Zea mays L.), many $Z m P H T s$ genes had been identified, and some transcription factors (TFs) were also found to be involved in the transcriptional regulation of $\mathrm{Pi}$ transporters, including myeloblastosis viral oncogene homolog (MYB)-type and basic Helix-Loop-Helix (bHLH)-type [27]. As a member of the MYB superfamily, phosphate starvation response 1 (PHR1) is a major TF involved in Pi signaling, which binds to the PHR1-binding sequence (P1BS) or P1BS-like domain and regulates the expression of many relevant genes under LP condition, including PHT1, Phosphate 1 (PHO1), and microRNA399 [27-30]. In Arabidopsis, PHR1 interacts with SPX domain proteins in the Pi-dependent manner. Under Pi-sufficient conditions, AtPHR1 has high binding with AtSPX1 to inhibit its Pi starvation-induced targets via P1BS, while weak binding with AtSPX1 to induce the PHR1 target gene expression under Pi-starved conditions [31-34]. In rice, SPXs regulate PHR2 activity in different subcellular levels to regulate $\mathrm{Pi}$ signaling. Under high cellular Pi status, as a negative regulator of PHR2, OsSPX4 also function in a $\mathrm{Pi}$ dependent way to inhibit PHR2 function; under Pi starvation, OsSPX4 would be degraded, and then OsPHR2 is released into the nucleus and activated Pi-responsive genes expression [35]. Recent report showed that SPX-domain proteins possibly involved in sensing the cellular Pi status by binding to PP-InsPs to regulate Pi homeostasis [36]. However, it needs to be investigated whether SPX-domain proteins are the internal Pi sensors next. Thus, how plants senses the external and internal Pi status remains to be uncover and the sensor have not been verified.

In addition, $\mathrm{P}$ nutrition displays various biological interplays with other nutrient pathways, such as the nutrition of nitrogen [37], sulfate [38], zinc [39], iron [40], sucrose, and hormones [41-43], related to the above-mentioned PHT1 members and TFs. Recently, P or Pi was reported to affect arsenic uptake, copper, and aluminum toxicity; citrate synthesis; and starch morphology [44-48]. In maize, global transcriptomic and metabonomic analyses identified multiple Pi-responsive genes that are mostly involved in metabolic pathways and biosynthesis of secondary metabolites and ion transport [49-52]. Nevertheless, the complete Pi signalling and uptake pathways, including how plants sense $\mathrm{Pi}$ levels internally by the putative phosphate receptors and the accurate regulatory network of PHT1 transporters, and the cross-talks between Pi and other pathways, are still unclear and need to be further elucidated.

Here, we firstly performed a comparative proteomic analysis of a maize genotype's response to long-term exposure to external LP and high-Pi (HP) levels. Our goal was to identify several key Pi-responsive proteins related to Pi uptake and transport under different Pi conditions, which may be applied for agricultural production using gene engineering techniques to overexpress one or more of these proteins' encoding genes in maize. Given the extensive post-transcriptional regulation, the analysis of protein levels may not reflect the transcription levels of genes but closely reflect their functions. Therefore, this study will not only enhance our understanding of the mechanism associated with the response of maize to different $\mathrm{Pi}$ levels, but also substantially explore the candidates in breeding the desired gene-modified agricultural crops.

\section{Methods}

\section{Materials and treatments}

QXN233, as a LP-tolerant maize genotype, was reserved in our laboratory [52]. Its seeds were surface sterilized with $10 \%(v / v) \mathrm{NaClO}$ for $5 \mathrm{~min}$, washed with distilled water repeatedly for three times, and then germinated on a wet gauze placed in a plastic square tray for two days. Subsequently, using a quartz sand or vermiculite assay, the uniform seedlings were transferred to a plastic round pot $(9 \mathrm{~cm} \times 21 \mathrm{~cm} \times 18 \mathrm{~cm}$, two plants in each pot) filled with quartz sand or vermiculite by irrigating with the normal solution $\left(2 \mathrm{mM} \mathrm{Ca}\left(\mathrm{NO}_{3}\right)_{2} \cdot 4 \mathrm{H}_{2} \mathrm{O}, 1.25\right.$ $\mathrm{mM} \mathrm{NH} \mathrm{NH}_{3}, 650 \mu \mathrm{M} \mathrm{MgSO} \cdot 7 \mathrm{H}_{2} \mathrm{O}, 650 \mu \mathrm{M} \mathrm{K}_{2} \mathrm{SO}_{4}$, $500 \mu \mathrm{M} \mathrm{KH}_{2} \mathrm{PO}_{4}, 100 \mu \mathrm{M} \mathrm{KCl}, 100 \mu \mathrm{M}$ Fe-EDTA, $10 \mu \mathrm{M}$ $\mathrm{mM} \mathrm{H}_{3} \mathrm{BO}_{4}, 1 \mu \mathrm{M} \mathrm{MnSO}_{4}, 1 \mu \mathrm{M} \mathrm{ZnSO} \mathrm{Zn}_{4} \cdot 7 \mathrm{H}_{2} \mathrm{O}, 0.1 \mu \mathrm{M}$ $\mathrm{CuSO}_{4} \cdot 5 \mathrm{H}_{2} \mathrm{O}$, and $\left.0.5 \mu \mathrm{M}\left(\mathrm{NH}_{4}\right)_{6} \mathrm{Mo}_{7} \mathrm{O}_{24}\right)$. The solutions were applied at 2-3-day intervals. The seedlings were cultivated in a controlled chamber with the temperatures of $28{ }^{\circ} \mathrm{C} \pm 2{ }^{\circ} \mathrm{C}$, relative humidity of $65 \%$, and a photoperiod of $14 \mathrm{~h}$ day $/ 10 \mathrm{~h}$ night photoperiod. At the three-leaf stage, seedlings were exposed to LP $\left(0 \mu \mathrm{M} \mathrm{KH} \mathrm{H}_{2} \mathrm{PO}_{4}\right)$ or $\mathrm{HP}\left(3 \mathrm{mM} \mathrm{KH}_{2} \mathrm{PO}_{4}\right)$ treatment, with $500 \mu \mathrm{M} \mathrm{KH}{ }_{2} \mathrm{PO}_{4}$ as the control. A total of $0.5 \mathrm{~L}$ of nutrient solutions containing different Pi levels were applied every two days. After being treated for 20 or 30 days, the plants were photographed and harvested.

For a hydroponic culture, the newly-germinated seedlings were de-embryonated and transferred to moderate grass containers with the normal solution and cultivated in the above chamber. The nutrient solution was changed every day. At the three-leaf stage, seedlings were treated under LP and HP conditions for 12 or $30 \mathrm{~h}$, and 
then the plants were detected and harvested. A quartz sand or a hydroponic assay was performed due to its less disturbed factors and later easily to rinse the roots.

All the experiments described had at least three biological replicates, and 6-12 plants were used for each replicate.

\section{Plant growth parameter and chemical analysis}

Using a quartz sand assay, at 20 days after the onset of treatment, plant height and leaf length and leaf width were measured by a ruler, and then the length of primary root and number of total roots were measured and counted. Afterward, the fresh weights (FWs) of shoots and roots were each weighed with electronic scales, respectively. Then, the shoots and roots quickly dried at $105^{\circ} \mathrm{C}$ for $20 \mathrm{~min}$ and then at $85^{\circ} \mathrm{C}$ for $48 \mathrm{~h}$ or until a fixed weight. Their the dry weights (DWs) of them were recorded and analyzed.

Using a vermiculite assay, the plants were divided into shoots and roots after 30 days of the treatments. On the basis of the plants' FWs, Pi content was analyzed by using the ammonium molybdate (Mo)-antimony potassium tartrate-ascorbic acid method as described previously [52]. On the basis of the plants' DWs, $\mathrm{Na}^{+}$and $\mathrm{K}^{+}$ contents were analyzed by flame atomic absorption spectroscopy after samples were digested using the $\mathrm{HNO}_{3}-\mathrm{H}_{2} \mathrm{O}_{2}$ method as previously described [53].
Malondialdehyde (MDA), compatible solutes contents, and superoxide dismutase (SOD) activity

Using a vermiculite assay, after 20 days of the treatments, the same parts of fresh leaves were harvested from the treated and control samples, quickly frozen in liquid nitrogen and stored at $-80^{\circ} \mathrm{C}$. MDA content was determined by a modified thiobarbituric acid method, proline was examined using the ninhydrin acid reagent method, and the soluble sugar and protein contents were estimated following the protocols described previously [53]. SOD activity was measured spectrophotometrically at $560 \mathrm{~nm}$ according to a previously reported method [53].

\section{$\mathrm{Na}^{+}$and $\mathrm{K}^{+}$fluxes}

Using a hydroponic assay, the seedlings were treated for $30 \mathrm{~h}$ under LP and HP conditions, and the mature zone of the root was used for the $\mathrm{Na}^{+}$and $\mathrm{K}^{+}$ion flux measurements by non-invasive micro-test technology (NMT) as described previously [53].

\section{RNA extraction and quantitative real-time polymerase chain reaction (qRT-PCR) analysis}

The seedlings were treated for $12 \mathrm{~h}$ under LP and HP conditions by using the above-mentioned hydroponic assay. The leaves and roots were collected from the treated and controlled samples, and then they were
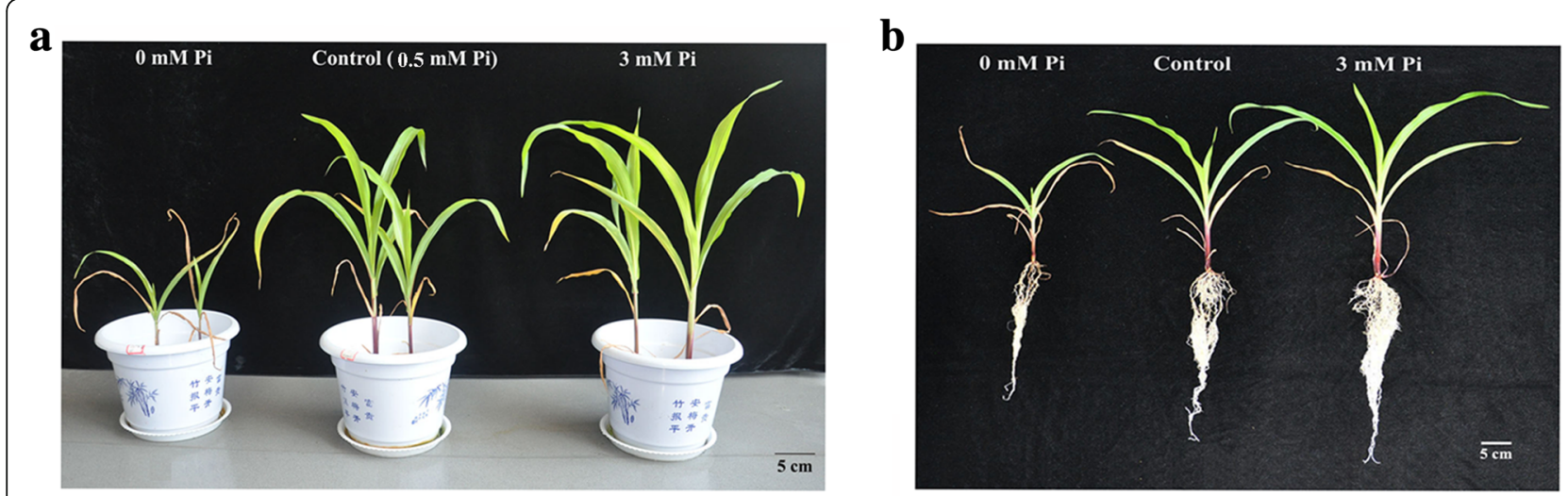

c

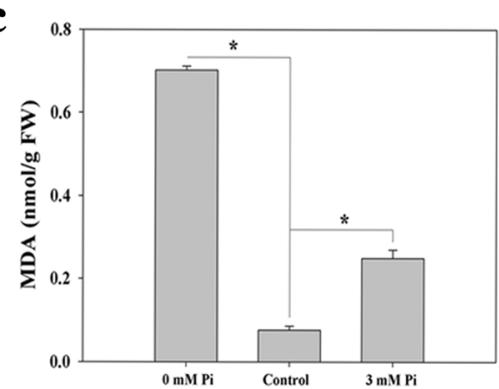

d

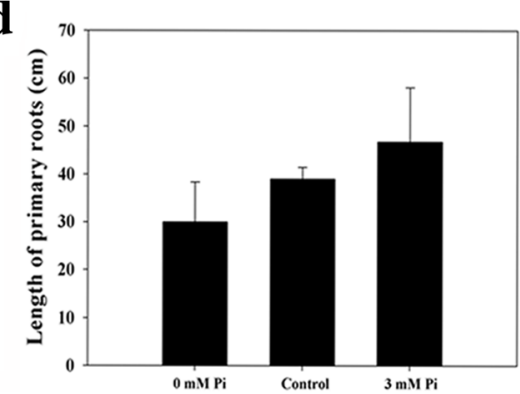

e

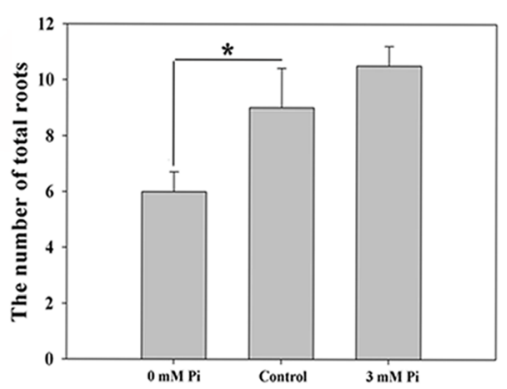

Fig. 1 Phenotypic responses and physiological changes when QXN233 was exposed for 20 days to low Pi (LP, 0 mM Pi), control (0.5 mM Pi), and high Pi (HP, $3 \mathrm{mM} \mathrm{Pi}$ ) conditions using a quartz sand assay. a Above-ground phenotypes; b under-ground phenotypes; $\mathbf{c}$ MDA; $\mathbf{d}$ length of primary roots; e the number of total roots. Bar $=5 \mathrm{~cm}$. Values represent means \pm SEM of three replicates. Asterisks indicate a significant difference between the two tested groups (LSD test, $P<0.05)$ 
snap-frozen with liquid nitrogen and ground quickly. RNA was extracted using the E.Z.N.A Plant RNA Kit (OMEGA, USA), and cDNA was synthesized in accordance with the protocol of the $5 \times$ All-in-One RT MasterMix kit (ABM, Canada). qRT-PCR was performed on an ABI 7500 real-time PCR system (ABI, USA) by using the Ultra SYBR Mixture Kit following the manufacturer's instructions (CWBIO, China). $18 \mathrm{~s}$ rRNA was used as an internal reference gene, and the other primers used for qRT-PCR are all shown in Additional file 1: Table S1. The $2^{-\Delta \Delta \mathrm{Ct}}$ method was used to calculate for the relative expression of mRNA in the target genes.

\section{Proteomic data analysis}

After the seedlings were treated for 30 days under LP and HP conditions by a vermiculite pot experiment, the leaves and roots were collected and rinsed from the treated and controlled samples, frozen in liquid nitrogen and ground quickly, precipitated in TCA/acetone (1:9), and resuspended in SDT buffer (4\% SDS, $100 \mathrm{mM}$ Tris- $\mathrm{HCl}, 1 \mathrm{mM}$ DTT, $\mathrm{pH}$ 7.6). The lysate was sonicated and boiled for $15 \mathrm{~min}$. After centrifugation at $14,000 \times g$ for $40 \mathrm{~min}$, the supernatant was filtered with $0.22 \mu \mathrm{m}$ filters, analyzed using the BCA Protein Assay Kit (Bio-Rad, USA), and stored at $-80^{\circ} \mathrm{C}$. A total of $20 \mu \mathrm{g}$ of proteins for each sample was separated on $12.5 \%$ SDS-PAGE, and protein bands were stained with coomassie blue R-250. Then, filter-aided sample preparation digestion was performed as described previously [54]. A total of $100 \mu \mathrm{g}$ of peptide mixture of each sample was labeled using tandem mass tag (TMT) reagent following the manufacturer's instructions (Thermo Fisher Scientific). TMT-labeled samples were divided into 10 fractions by using Pierce High pH Reversed-Phase Peptide Fractionation Kit (Thermo scientific).

Each prepared fraction was injected for nano-liquid chromatography-mass spectrometry (LC-MS)/MS analysis. The peptide mixture was loaded onto a reversed
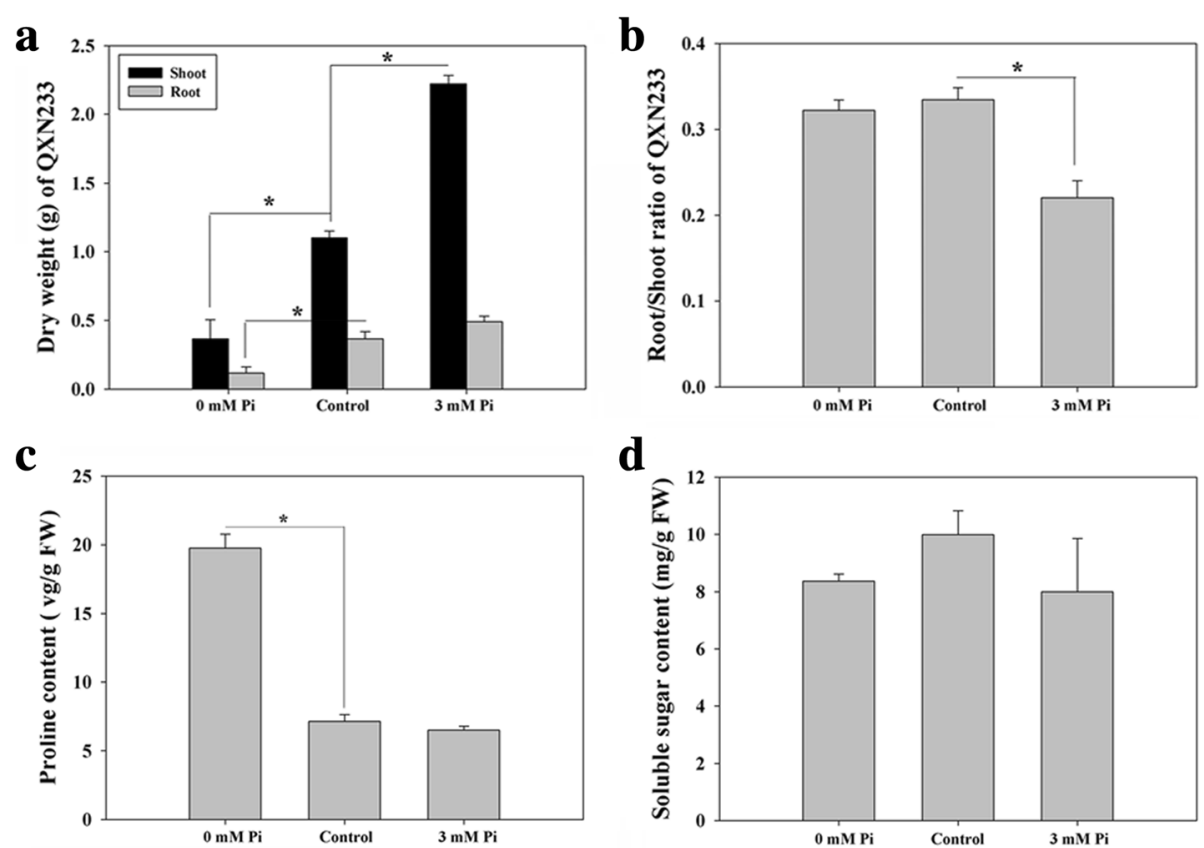

d
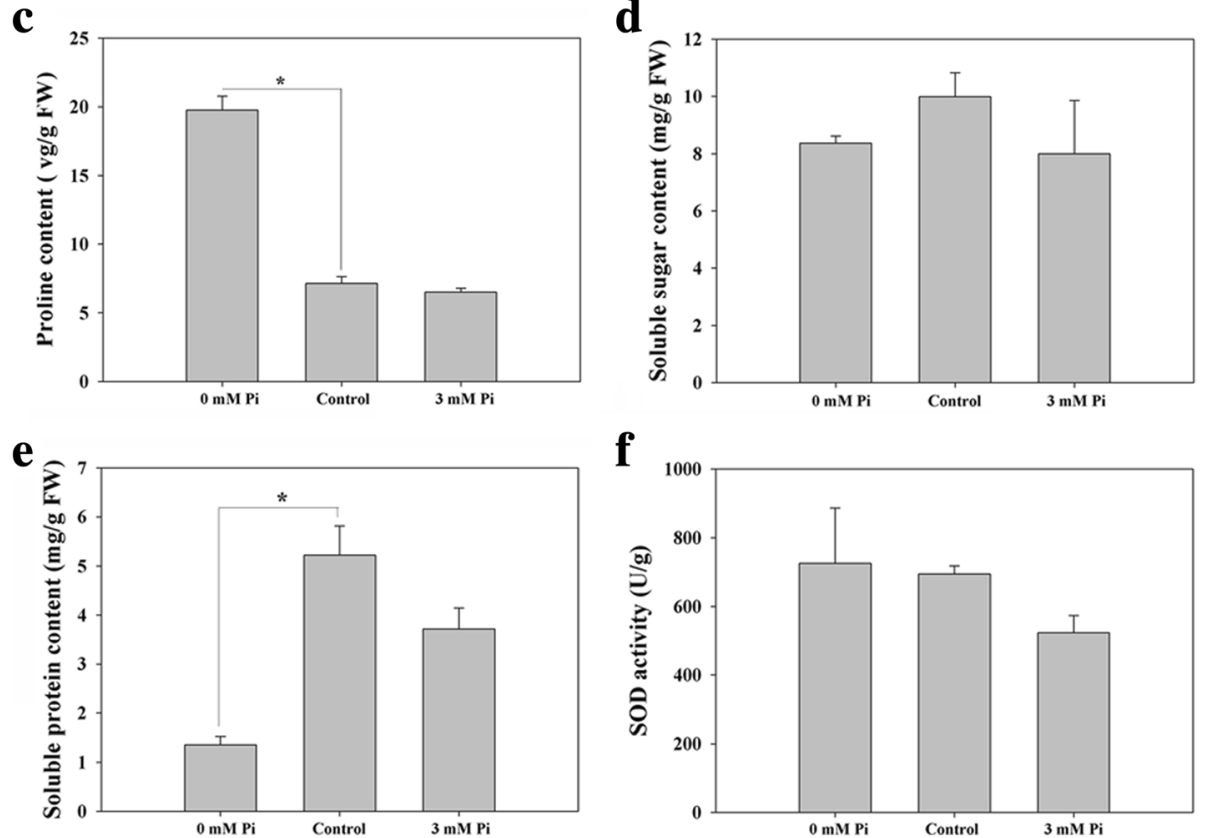

Fig. 2 Quantitative analyses of DW, compatible solutes contents and SOD activity in QXN233 after 20 days under LP and HP conditions. a DWs of shoots and roots; (b) root/shoot ratio; (c) proline content; (d) soluble sugar content; (e) soluble protein content; (f) SOD activity. Values represent means \pm SEM of three replicates. Asterisks indicate a significant difference between the two tested groups (LSD test, $P<0.05$ ) 
Table 1 Quantitative analyses of plant height and the width and length of the longest leaf, and FWs of the shoots and roots in QXN233 after 20 days under $0 \mathrm{mM}$ Pi or $3 \mathrm{mM}$ Pi treatment by a quartz sand assay

\begin{tabular}{llllll}
\hline QXN233 & Plant height $(\mathrm{cm})$ & Width of the longest leaf $(\mathrm{cm})$ & Length of the longest leaf $(\mathrm{cm})$ & FW of shoots $(\mathrm{g})$ & FW of roots $(\mathrm{g})$ \\
\hline 0 mM Pi & $17^{*} \pm 4.0$ & $2 \pm 0.3$ & $23^{*} \pm 3.0$ & $2.813^{*} \pm 0.1$ & $2.279^{*} \pm 0.4$ \\
Control & $33 \pm 6.0$ & $3 \pm 0.1$ & $33 \pm 4.0$ & $7.688 \pm 0.5$ & $5.441 \pm 0.3$ \\
$3 \mathrm{mM} \mathrm{Pi}$ & $40.5 \pm 4.9$ & $4 \pm 0.2$ & $46.75^{*} \pm 4.6$ & $13.673^{*} \pm 1$ & $8.574^{*} \pm 0.6$
\end{tabular}

Values represent means \pm SEM of three replicates. Asterisks indicate a significant difference between the Pi-treated and control group $(t$-test, $P<0.05$ )

phase trap column (Thermo Scientific Acclaim PepMap 100, Nano Viper C18, $100 \mu \mathrm{m} * 2 \mathrm{~cm}$ ) connected with the analytical column of a C18-reversed phase Thermo Scientific Easy Column (length: $10 \mathrm{~cm}$, inner diameter: $75 \mu \mathrm{m}$, resin: $3 \mu \mathrm{m})$ in buffer solution A $(0.1 \%$ formic acid) and separated through a linear gradient of buffer solution B ( $84 \%$ acetonitrile and $0.1 \%$ formic acid) at a flow rate of $300 \mathrm{nl} / \mathrm{min}$ controlled by IntelliFlow technology. The $1.5 \mathrm{~h}$ gradient was determined as follows: $0-55 \%$ buffer B for $80 \mathrm{~min}, 55-100 \%$ buffer B for $5 \mathrm{~min}$, and then held in $100 \%$ buffer B for $5 \mathrm{~min}$. LC-MS/MS analysis was carried out on a Q Exactive mass spectrometer (Thermo Scientific) coupled to Easy nLC (Proxeon Biosystems, now Thermo Fisher Scientific, USA) for $90 \mathrm{~min}$. MS was performed in positive ion mode. The mass spectrometer was acquired with a data-dependent top 10 method dynamically choosing the most abundant precursor ions from the survey scan $(300-1800 \mathrm{~m} / \mathrm{z})$ for higher-energy collisional dissociation (HCD) fragmentation. The automatic gain control target was set to $3 \mathrm{e} 6$, the maximum injection time to $10 \mathrm{~ms}$, and the dynamic exclusion duration was $40.0 \mathrm{~s}$. Survey scans were acquired at a resolution of 70,000 at $200 \mathrm{~m} / \mathrm{z}$, the HCD spectrum was set to 17,500 at $200 \mathrm{~m} / \mathrm{z}$ (TMT 6 plex), and the isolation width was $2 \mathrm{~m} / \mathrm{z}$. The normalized collision energy was $30 \mathrm{eV}$, and the underfill ratio was $0.1 \%$, which specifies the minimum percentage of the target value likely to be reached at maximum fill time. The instrument was run with peptide recognition mode enabled.

MS/MS spectra were searched using MASCOT engine (version 2.2, Matrix Science, London, UK) embedded into Proteome Discoverer 1.4. Decoy database was used for the false discovery rate (FDR) calculation and data with FDR $\leq 0.01$ were filtered. The statistical significance of quantitative data was determined using Student's $t$-test $(n=3, P<0.05)$, and the different expressed proteins (DEPs) between the LP/HP treatment and control groups were defined as $P<0.05$ and ratio $>1.2$ (up/down regulated). On the basis of Fisher's exact test, Gene
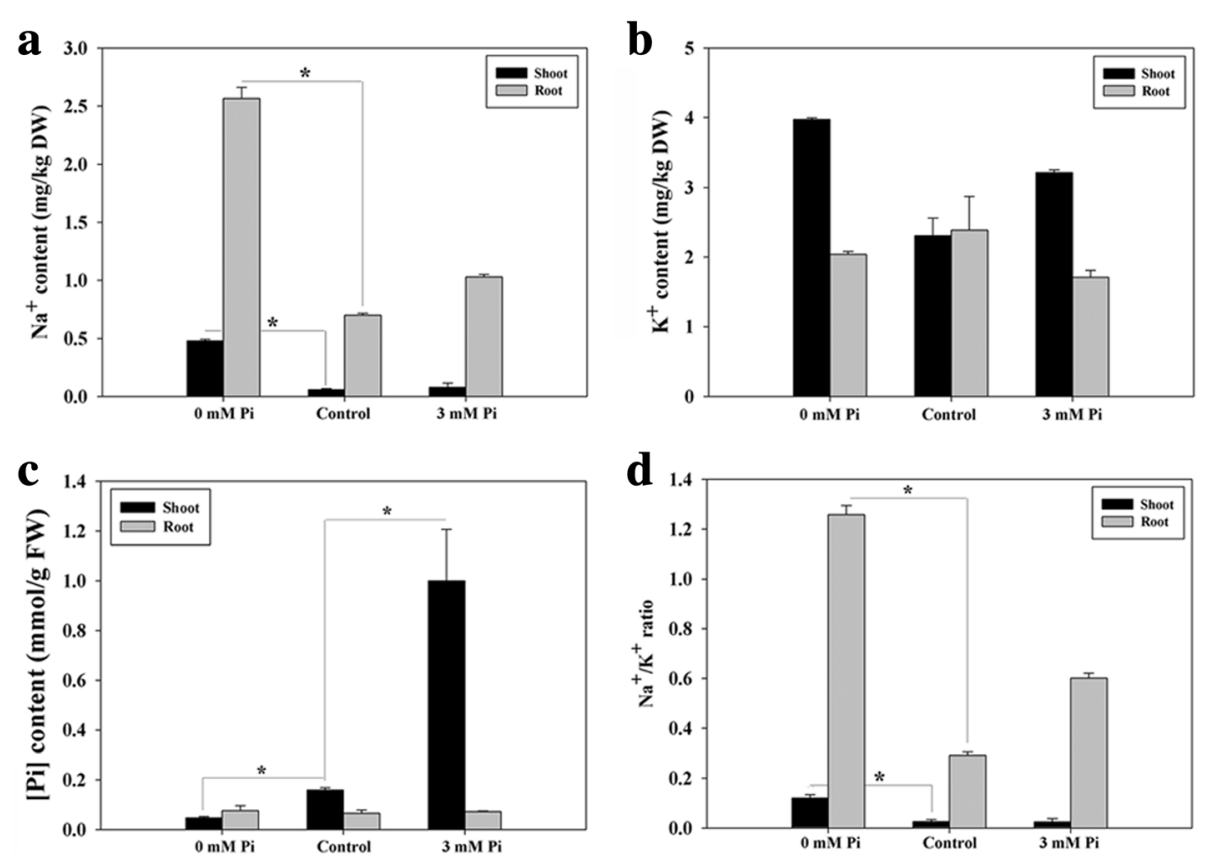

Fig. 3 Changes in $\mathrm{Na}^{+}(\mathbf{a}), \mathrm{K}^{+}(\mathbf{b})$, and $\mathrm{Pi}(\mathbf{c})$ ion content and $\mathrm{Na}^{+} / \mathrm{K}^{+}$ratio (d) in QXN233 exposed for 30 days to the control, $\mathrm{LP}$ and $\mathrm{HP}$ conditions. Values represent means \pm SEM of three replicates. Asterisks indicate a significant difference between the two tested groups (LSD test, $P<0.05)$ 
Ontology (GO) enrichment on three ontologies (biological process, molecular function, and cellular component) and Kyoto Encyclopedia of Genes and Genomes (KEGG) pathway enrichment analyses were analyzed to explore the impact of DEPs in cell physiological process.

\section{Data analysis}

Three biological replicates were applied for all the above experiments, and the data were reported as means \pm standard error (SEM). The statistical software program used was SPSS version 18.0. All data obtained were subjected to ANOVA, and the significance difference between the two tested groups was determined by $P$ value ("means $P<0.05$ ) on the basis of least-significant difference (LSD) test.

\section{Results}

Plant growth and the physiological response under LP and HP conditions

Under LP condition, QXN233 displayed an obviously inferior phenotype whereas a superior performance under HP condition (Fig. 1a, b; Additional file 1: Figures S1, S2). QXN233 leaves accumulated a large amount of MDA under LP condition, suggesting that severe cell damage occurred in its leaves (Fig. 1c). With the addition of external Pi concentration, the primary root elongated, and the number of total roots also significantly increased (Fig. 1d, e). The plant height, leaf-width and -length, and FWs and DWs increased (Fig. 2a, b; Tables 1, Additional file 1: Table S2). The lowest root/shoot ratio was found in QXN233 under HP condition (Fig. 2b, right), indicating that shoot growth was promoted by sufficient Pi application.

In addition, when exposed to LP condition, QXN233 accumulated higher proline content but less soluble protein content than those of the control or HP group, and no significant difference was found between soluble sugar content and SOD activity among the three $\mathrm{Pi}$ levels (Fig. 2c-f).

\section{$\mathrm{Na}^{+}, \mathrm{K}^{+}$, and pi distributions and relevant gene expression under LP and HP conditions}

To further investigate the ion distributions of QXN233 seedlings under different $\mathrm{Pi}$ conditions, $\mathrm{Na}^{+}, \mathrm{K}^{+}$, and $\mathrm{Pi}$ contents were measured in shoots and roots. Under LP condition, the $\mathrm{Na}^{+}$content in the shoots and especially, the roots increased, whereas no significant difference was found in terms of $\mathrm{K}^{+}$content, resulting in a high $\mathrm{Na}^{+} / \mathrm{K}^{+}$ratio (Fig. 3a, b, d). In contrast to LP stress, a low $\mathrm{Na}^{+}$content and $\mathrm{Na}^{+} / \mathrm{K}^{+}$ratio showed in plants under HP condition, especially in shoots, although no significant change compared to the control (Fig. 3a, d). Obviously, the Pi content in QXN233 shoots increased as the external Pi supplement increased, and the highest content was observed at the $3 \mathrm{mM}$ Pi condition (Fig. 3c), indicating a strong Pi uptake and assimilation by shoot cells. Of note, low $\mathrm{Na}^{+}$was found in shoots under $\mathrm{HP}$ condition (Fig. 3a, c), indicating a negative relationship between $\mathrm{Na}^{+}$and $\mathrm{Pi}$ in the shoots.
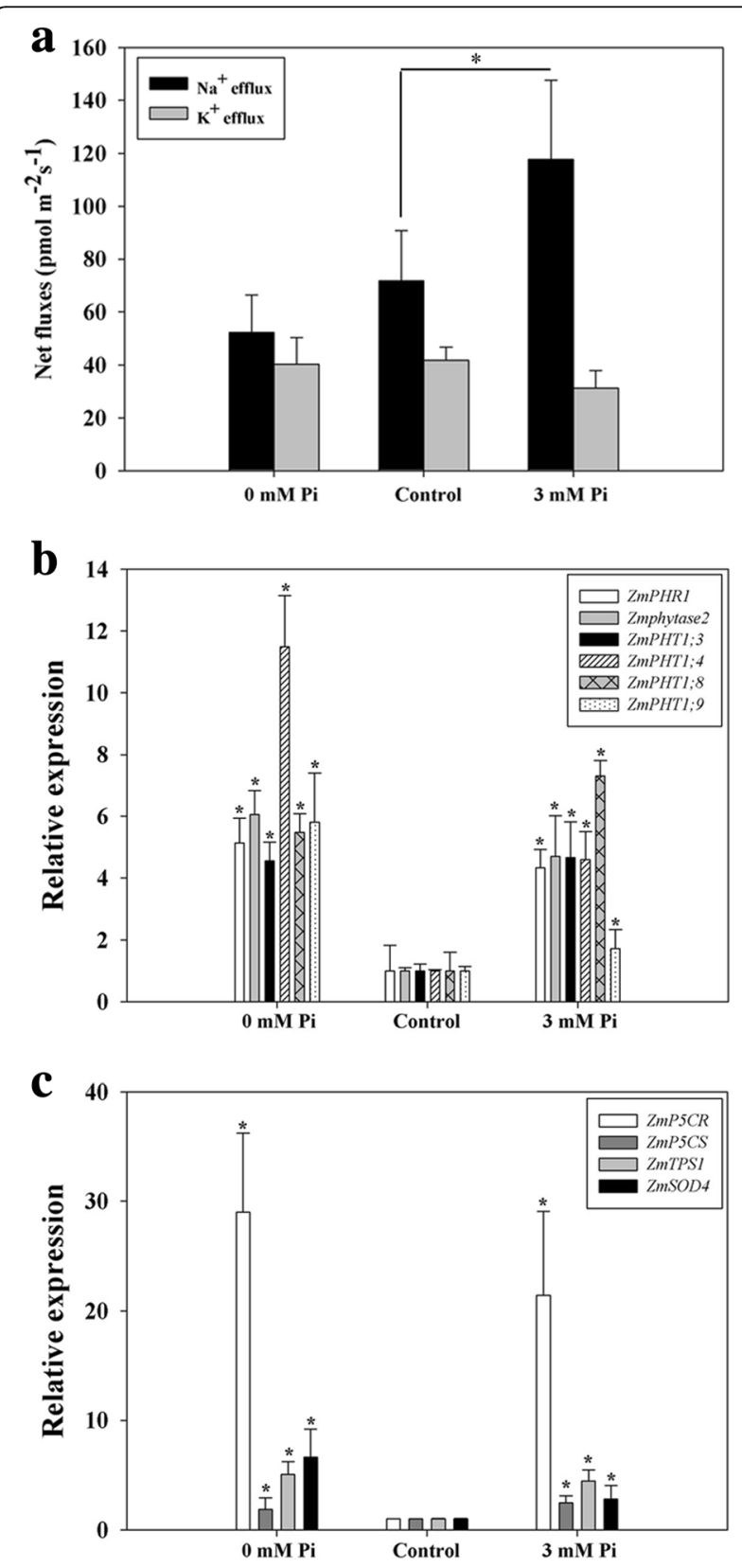

Fig. 4 Changes in net $\mathrm{Na}^{+}$and $\mathrm{K}^{+}$fluxes (a) and gene expression analysis (b and $\mathbf{c}$ ) of QXN233 under LP and HP conditions. Ion fluxes were measured in the root mature zones of QXN233 exposed to control, LP and HP conditions for $30 \mathrm{~h}$, and the relative gene expressions were detected by qRT-PCR in QXN233 roots after $12 \mathrm{~h}$ under LP and HP treatments. Values represent means \pm SEM of three replicates. Asterisks indicate a significant difference between the two tested groups $($ LSD test, $P<0.05)$ 


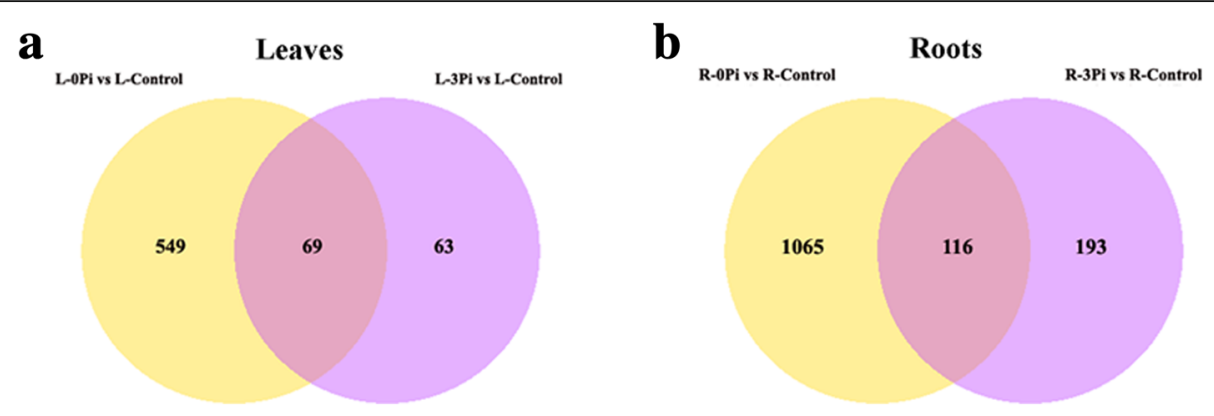

Fig. 5 Distribution of DEPs in leaves (a) and roots (b) under LP and HP conditions
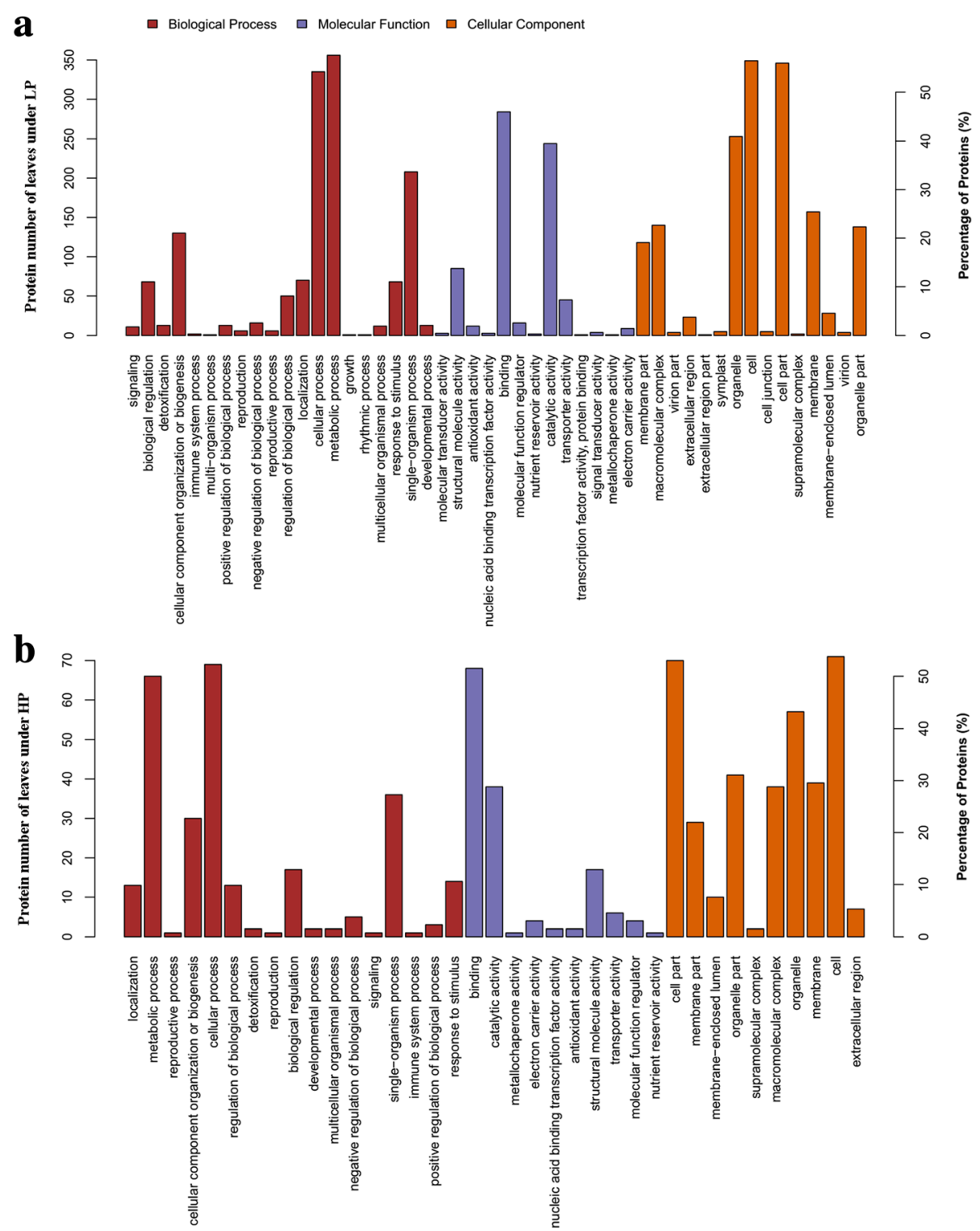

Fig. $6 \mathrm{GO}$ categories of DEPs on the basis of GO enrichment analysis in leaves under LP (a) and HP (b) conditions 
Moreover, $\mathrm{Na}^{+}$and $\mathrm{K}^{+}$ion fluxes were detected using NMT at $30 \mathrm{~h}$ after QXN233 roots were exposed to LP and HP conditions, respectively. The result showed that a high $\mathrm{Na}^{+}$efflux emerged in the roots under HP condition (Fig. 4a), implying that high $\mathrm{Na}^{+}$exclusion was induced by HP supplementation. Furthermore, the Pi-responsive genes, including the early gene $Z m P H R 1$ and the Pi transporters ZmPHT1;3 (GRMZM2G112377), ZmPHT1;4 (GRMZM2G170208), ZmPHT1;8 (GRMZM2G045473), ZmPHT1;9 (GRMZM2G154090), and Zmphytase2 were all upregulated under LP and HP conditions (Fig. 4b), especially for ZmPHT1;9 (GRMZM2G154090), as the encoding gene of Q49B46 detected in below proteomic analysis. This result suggested that these genes play important roles in Pi uptake and homeostasis. The gene encoding proline synthesis Zea mays pyrroline-5carboxylate reductase ( $\mathrm{ZmP5CR}$ ) was also upregulated under both LP and HP conditions, which is similar to the other related genes, including Zea mays pyrroline5-carboxylate synthetase ( $\mathrm{ZmP5CS}$ ), as well as Zea mays trehalose-6-phosphate synthase (ZmTPS1) and Zea mays superoxide dismutase (ZmSOD4), which encode enzymes involved in the trehalose and SOD biosynthesis pathway, respectively (Fig. 4c), This finding implied that these genes play an important role for osmotic adjustment under Pi starvation and excess $\mathrm{Pi}$ supplementation providing nutrition also induces slight stress to plant cells.

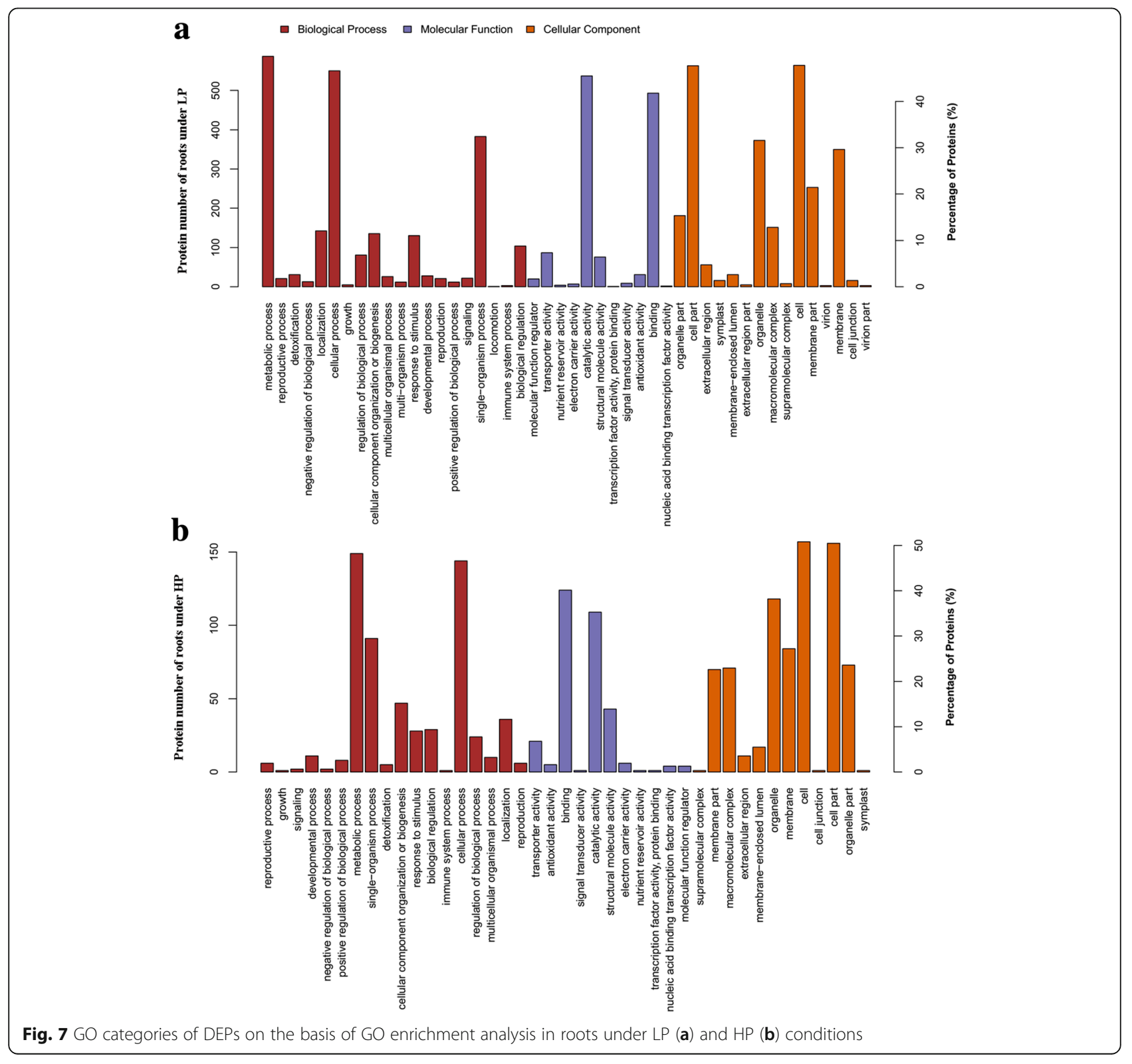


Proteome analysis of QXN233 under LP and HP conditions To gain more insights into the regulated mechanism of QXN233 response to long-term LP or HP conditions, we performed quantitative proteomic analysis in its leaves and roots by TMT technology. Compared with normal condition, the DEP profiles under LP or HP condition were identified. A total 681 DEPs in the leaves and 1374 DEPs in the roots, and 69 overlapped DEPs in the leaves and 116 overlapped DEPs in the roots were generated (Fig. 5; Additional file 1: Tables S3, S4). Furthermore, under LP and HP conditions, GO analysis in QXN233 both showed that the main biological processes were involved in the metabolic and cellular process, and the main molecular function related to the binding and the main catalytic activity (Figs. 6, 7). KEGG analysis also revealed that the major pathways were both associated with ribosomes in the leaves and roots of QXN233 under LP or HP condition, indicating that Pi plays a vital role in the ribosomes (Figs. 8, 9). Moreover, some important encoding genes of DEPs were confirmed by qRT-PCR, most of them were upregulated under LP condition while downregulated or no significant change under HP condition (Fig. 10). Thus, the level of their transcript in leaves or roots corresponded to the proteomic analysis of maize in response to LP and HP conditions (Fig. 10; Table 2), implying that the proteomic analysis is reliable.

\section{DEPs involved in various metabolic and signal pathways}

On the basis of the predicted functions, many DEPs were presented and classified into different groups (Additional file 1: Table S3), including metabolism, photosynthesis, ATP metabolism, transcriptional regulators, translation, cell growth, phytohormone regulation, oxidation-reduction process, and stress response. Compared with HP condition, we found that the majority of DEPs involved in metabolism, photosynthesis, and ATP metabolism were highly expressed in QXN233 leaves under LP stress, suggesting that Pi deficiency has important effects on these aspects. Similarly, under LP stress, many DEPs associated with oxidation-reduction and stress response were both upregulated in the leaves and roots, including SOD, peroxidase, heat shock $70 \mathrm{kDa}$ protein, and aquaporin, suggesting possible strategies in

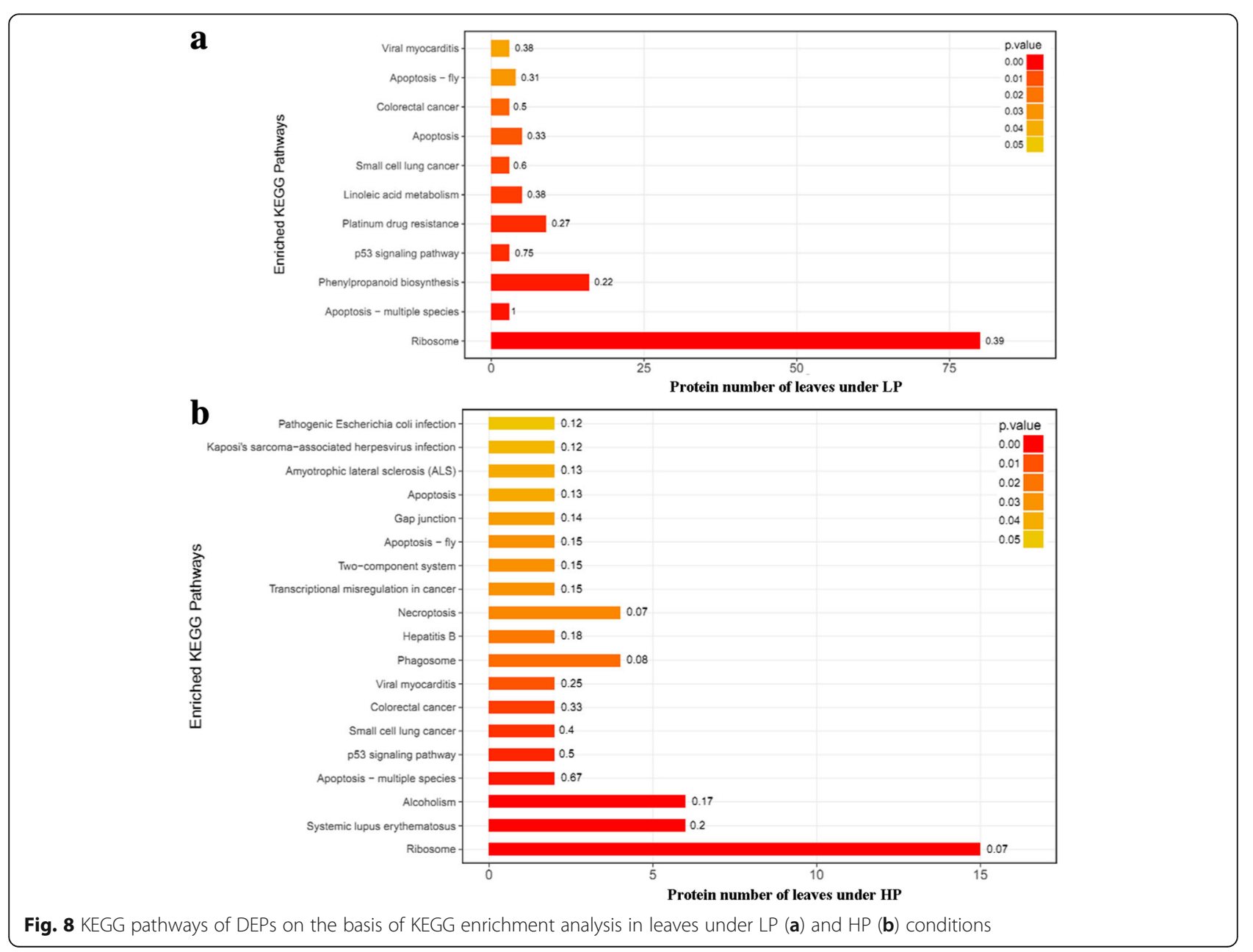




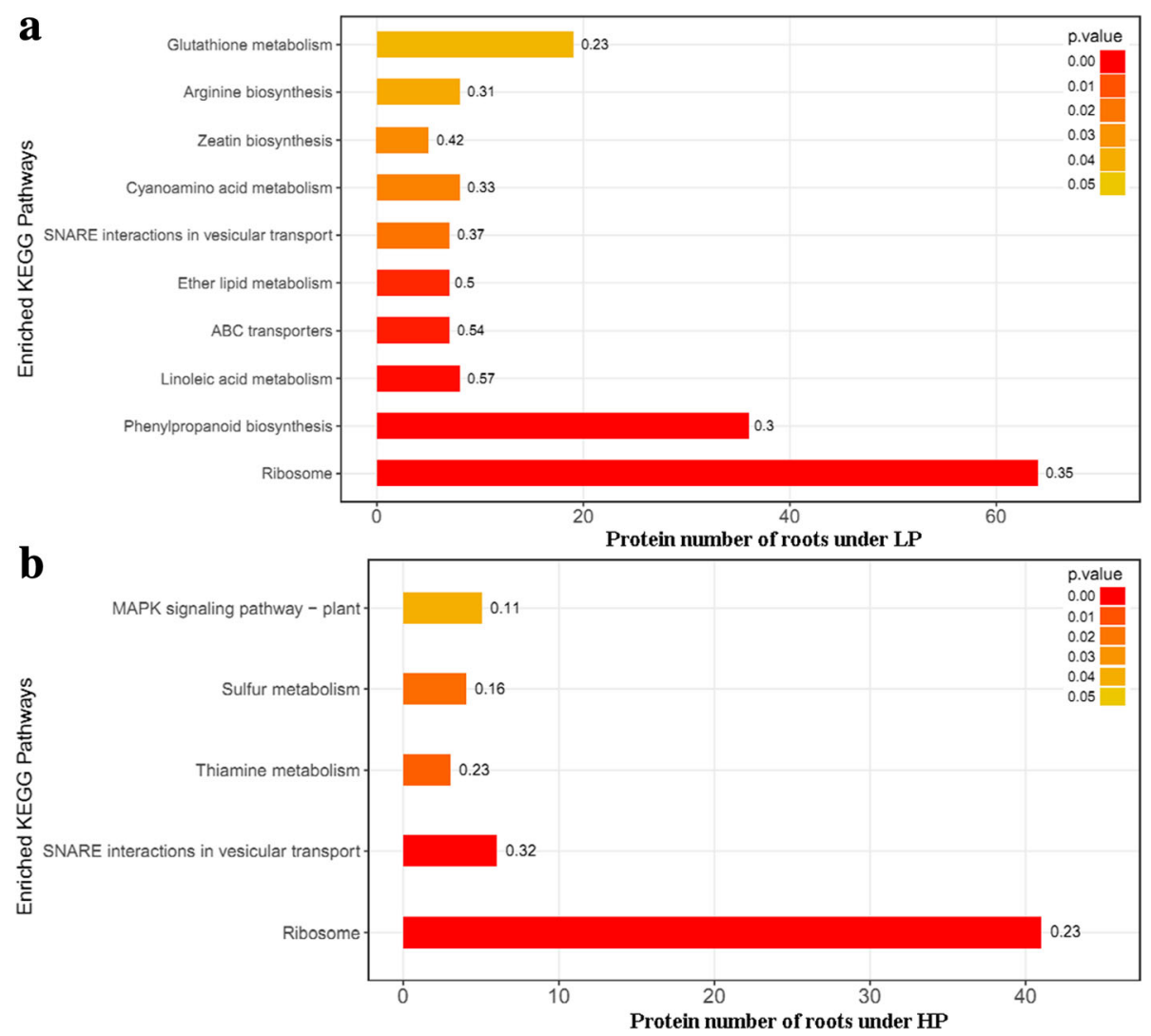

Fig. 9 KEGG pathways of DEPs on the basis of KEGG enrichment analysis in roots under LP (a) and HP (b) conditions

response to Pi deficiency. Moreover, some DEPs involved in the phytohormone regulation, were increased in leaves or roots, including abscisic acid, brassinosteroid, and gibberellic acid, were increased in the leaves or roots, suggesting that phytohormones participate in the LP response. By contrast, DEPs associated with $40 \mathrm{~S}$ and $60 \mathrm{~S}$ ribosomal assembly were downregulated in the leaves and roots under LP stress (Additional file 1: Tables S3, S4), indicating a decrease in ribosomal activity due to Pi deficiency. In addition, the expression patterns of DEPs related to cell growth, including K7W5K6 (pectinesterase), A0A077D360 (cellulose synthase) and B6TH29 (cell division protein ftsZ) which were downregulated in the leaves under LP stress (Additional file 1: Table S3), probably led to the weak growth performance under Pi deficiency, were intricate and need to be studied further.

\section{Key DEPs related with pi transport under LP and HP conditions}

Under LP condition, Q6GUH9 (phosphate transport protein), Q49B46 (inorganic phosphate transporter 1), and C4JC09 (phosphate transporter protein 9) were upregulated in the leaves or roots but downregulated under HP condition (Table 2). Moreover, two purple acid phosphatases (PAPs), B4F9L6 and A0A1D6KE94, presented the same trends as the above Pi transporters, which freed Pi from phytase-P (Table 2), suggesting that these proteins play vital roles in Pi assimilation, transport and remobilization. Except for the common DEPs, B6SYB8 (Pi starvation-induced protein, fold change $=1.29$ in leaves), A0A1D6QB24 (phosphate transporter 2, fold change $=2.4$ in roots), and A0A1D6HFX1 (SPX domain-containing membrane protein, fold change $=1.35$ in roots) were also uniquely increased under LP condition (Table 3), suggesting their contribution to $\mathrm{Pi}$ acquisition. Moreover, some PAPs, A0A1D6EDB6 (fold change $=1.57$ in leaves) and K7TEL4 (fold change $=2.14$ in roots), and B6TWW2 (fold change $=0.63$ in roots) were also up-/downregulated accordingly in LP/HP condition, but B4FR72 (fold change $=0.75$ in roots) requires further study (Table 3 ).

Furthermore, searching from Uniprot (https://www.uni prot.org/) and NCBI (https://www.ncbi.nlm.nih.gov/) database, some DEPs'encoding genes were analyzed, including Q6GUH9 (ZmPHT1, GRMZM2G326707), Q49B46 (ZmPHT1;9/ZmPHT2, GRMZM2G154090), C4JC09 (ZmPHT9, GRMZM2G070087), B4F9L6 (ZmPAP10, GRMZM2G093101), A0A1D6KE94 [nucleotide pyrophosphatase/phosphodiesterase (ZmNPP), GRMZM2G315848], and A0A1D6HFX1 (ZmSPX, GRMZM2G166976). The expression levels of these genes were examined by qRT-PCR. The results 

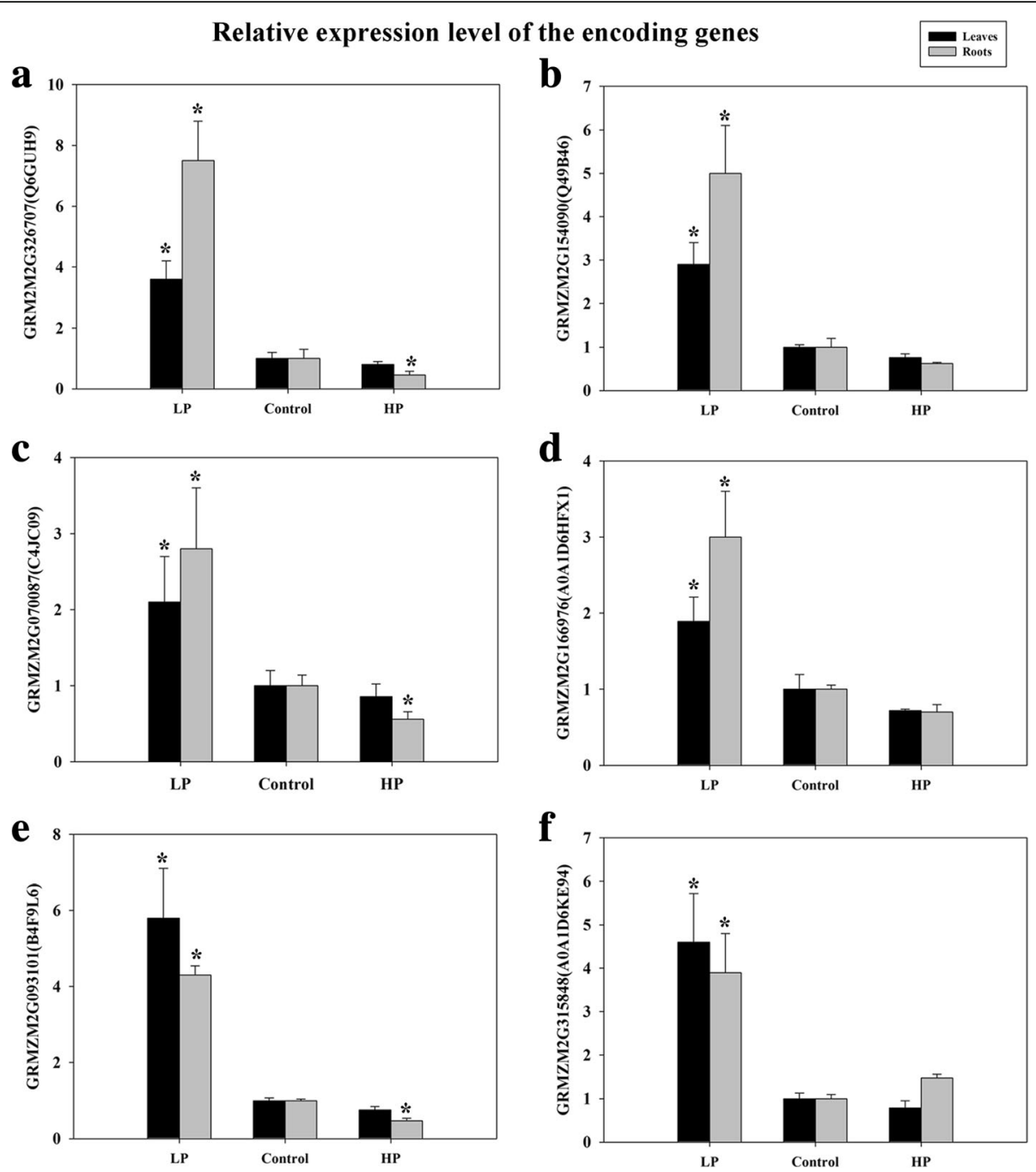

Fig. 10 Validation of the gene expression profiles from the DEPs identified by proteomic analysis using qRT-PCR. Relative expressions of six tested Pi-responsive genes in leaves and roots are shown under LP and HP conditions. a GRM2M2G326707 (Q6GUH9); (b) GRMZM2G154090 (Q49B46); (c) GRMZM2G070087 (C4JC09); (d) GRMZM2G166976 (AOA1D6HFX1); (e) GRMZM2G093101 (B4F9L6); (f) GRMZM2G315848 (A0A1D6KE94). Values represent means \pm SEM of three replicates. Asterisks indicate a significant difference between the two tested groups (LSD test, $P<0.05)$

showed that ZmPHT1, ZmPHT2, and ZmPHT9 increased in leaves or roots under LP condition while decreased under HP condition, consistent with the results of proteomic analysis (Fig. 10a-c; Table 2). Similarly, the expression patterns of ZmPAP10, ZmNPP, and ZmSPX were also nearly in accordance with the changing trend of the relevant protein levels by proteomic analysis (Fig. 10d-f; Table 2).

Other transporters identified under LP and HP conditions Aside from the above transporters, many other transporters, including carbohydrate transporters, cation transporters, and ATP-binding cassette $(\mathrm{ABC})$ transporters, were also identified. Similarly, some of them presented opposite expression patterns under LP and HP conditions (Table 2). For carbohydrate transporters, COPHL2 (monosaccharide transporter1), K7TK04 (carbohydrate transporter/sugar porter), A0A1D6EP34 (sugar transport protein 14) and B6TZY0 (facilitated glucose transporter member 8), were increased under LP condition but suppressed under HP condition in the leaves or roots, indicating that these transporters regulated sugar metabolism when maize seedlings adapted to different Pi levels (Table 2). A0A1D6MQM6 and B6TCP1 (carbohydrate transporter/sugar porter/transporter), and A0A1D6IFG4 (sugar carrier protein C), A0A1D6MV11 (sucrose transporter 4), A0A1D6MLZ7 (plastidic glucose transporter 4), and three putative polyol transporters, were also induced under LP condition (Table 3).

For the cation transporters, two $\mathrm{K}^{+}$transporters, A0A1D6N218 (fold change $=1.42$ in roots) and W5UB74 (fold change $=1.26$ in roots), were elevated under LP condition, but B6T7A1 (voltage-gated $\mathrm{K}^{+}$channel beta 
Table 2 Differentially expressed transporters of QXN233 both identified under LP and HP compared with the normal condition by the proteomic analysis (Ratio $\mid 0$ Pi or $3 \mathrm{Pi} /$ Control $>1.2$ and $P$ value $<0.05$ )

\begin{tabular}{|c|c|c|c|c|c|}
\hline Accession number & Protein description & L-(OPi/Control) & L-(3Pi/Control) & $\mathrm{R}-(\mathrm{OPi} /$ Control) & R-(3Pi/Control) \\
\hline \multicolumn{6}{|c|}{ Pi-related transporters } \\
\hline Q6GUH9 & Phosphate transport protein & 1.53 & - & 1.32 & 0.79 \\
\hline Q49B46 & Inorganic phosphate transporter 1 & 1.49 & - & 1.94 & 0.79 \\
\hline C4JC09 & Phosphate transporter protein 9 & - & - & 1.25 & 0.62 \\
\hline B4F9L6 & Purple acid phosphatase & 2.2 & - & 1.84 & 0.62 \\
\hline A0A1D6KE94 & Purple acid phosphatase & 2.03 & - & 1.67 & 0.62 \\
\hline \multicolumn{6}{|c|}{ Carbohydrate transporters } \\
\hline COPHL2 & Monosaccharide transporter 1 & 1.72 & - & 1.33 & 0.83 \\
\hline K7TK04 & Carbohydrate transporter/ sugar porter & - & - & 4.655 & 0.61 \\
\hline A0A1D6EP34 & Sugar transport protein 14 & - & - & 1.4 & 0.78 \\
\hline B6TZYO & Facilitated glucose transporter member 8 & - & - & 1.38 & 0.77 \\
\hline \multicolumn{6}{|l|}{$A B C$ transporters } \\
\hline A0A1D6NEN5 & ABC transporter B family member 9 & 1.29 & - & 1.72 & 0.79 \\
\hline B4FBM3 & ABC transporter $\mathrm{G}$ family member 6 & - & - & 1.31 & 0.82 \\
\hline \multicolumn{6}{|l|}{ Other transporters } \\
\hline COP6NO & Calcium load-activated calcium channel & 0.74 & - & 0.73 & 1.65 \\
\hline Q61681 & Ascorbate-specific transmembrane electron transporter 1 & - & - & 1.39 & 0.83 \\
\hline
\end{tabular}

subunit) and A0A1D6DSW6 and A0A1D6JIE4 (two $\mathrm{K}^{+}$efflux antiporters, chloroplastic), responsible for $\mathrm{K}^{+}$transport and exclusion, were also induced. Moreover, two nitrate transporters, A0A1D6KAA6 (protein NRT1/PTR family 8.3 , fold change $=1.35$ in roots) and A0A1D6N629 (protein NRT1/PTR family 5.10, fold change $=0.68$ in roots), were detected in roots under LP condition. Many $\mathrm{ABC}$ transporters were also significantly altered in roots. Among them, A0A1D6NEN5 (ABC transporter B family member 9) and B4FBM3 (ABC transporter $G$ family member 6) showed opposite expression patterns in roots' response to LP and HP conditions (Tables 2, 3).

Interestingly, several other transporters were also identified. C0P6N0 (calcium load-activated calcium channel) was both downregulated in the leaves and roots under LP condition but upregulated in the roots under HP condition. Q6I681 [ascorbate (As)-specific transmembrane electron transporter 1] was up- and downregulated in roots under LP and HP conditions, respectively. Under LP condition, A0A096TR23 [molybdate (Mo) transporter 2] was highly expressed in the leaves and roots and A0A1D6PKM7 [boron (B) transporter 4] was lowly expressed in the leaves. These results indicated that high As and Mo and low B contents are required by plants under Pi deficiency (Table 3).

\section{Discussion}

Plants are usually subjected to Pi limitation, which hinders growth and development $[3,4,6]$. Several studies have investigated the regulated mechanism of plants response to Pi deficiency [7, 9-11], and most of them have focused on the gene changes, Few have reported on protein changes. In this study, the maize genotype QXN233, a LP-tolerant genotype as found in our previous report [52], was used to investigate the phenotypic and physiological responses to external LP and HP levels and further explore the regulated mechanism (Fig. 11). QXN233 displayed inferior and superior phenotypes under long-time LP and HP conditions, respectively (Fig. 1a, b; Additional file 1: Figs. S1, S2). The more Pi supplied, the better growth of QXN233 seedlings, as supported in various physiological indices (Fig. 1, 2; Tables 1, Additional file 1: Table S2). For instance, QXN233 accumulated MDA and proline under Pi deficiency, supported by ZmP5CR, ZmP5CS, ZmTPS1 and ZmSOD4 all upregulated after $12 \mathrm{~h}$ under LP condition, whereas MDA and proline levels were decreased under Pi sufficiency (Figs. 1c, 2c), suggesting that it recovered from LP osmotic stress. However, the protein level was low under LP condition, and no significant difference was observed in soluble sugar and SOD activity (Fig. 2d-f). This finding was probably because the plant had re-established a new balance during the long-term Pi treatment.

External Pi supplementation influenced other ion transports in plants. External Pi application has different effects on the salt tolerance of plants related to the uptake or exclusion of $\mathrm{Na}^{+}$or $\mathrm{K}^{+}$ion $[55,56]$. In the present study, we observed high $\mathrm{Na}^{+}$contents and no change in $\mathrm{K}^{+}$contents. High $\mathrm{Na}^{+} / \mathrm{K}^{+}$ratio emerged in 
Table 3 Differentially expressed transporters of QXN233 identified under LP or HP condition compared with the normal condition by the proteomic analysis (Ratio |0 Pi or $3 \mathrm{Pi} /$ Control| $>1.2$ and $P<0.05$ )

\begin{tabular}{|c|c|c|c|c|c|}
\hline Accession number & Protein description & L-(OPi/Control) & L-(3Pi/Control) & $\mathrm{R}-(\mathrm{OPi} /$ Control) & R-(3Pi/Control) \\
\hline \multicolumn{6}{|c|}{ Pi-related transporters } \\
\hline B6SYB8 & Pi starvation-induced protein & 1.29 & - & - & - \\
\hline A0A1D6QB24 & Phosphate transporter 2 & - & - & 2.4 & - \\
\hline A0A1D6HFX1 & SPX domain-containing membrane protein & - & - & 1.35 & - \\
\hline A0A1D6EDB6 & Purple acid phosphatase & 1.57 & - & - & - \\
\hline K7TEL4 & Purple acid phosphatase & - & - & 2.14 & - \\
\hline B4FR72 & Purple acid phosphatase & - & - & 0.75 & - \\
\hline B6TWW2 & Purple acid phosphatase & - & - & - & 0.63 \\
\hline \multicolumn{6}{|c|}{ Carbohydrate transporters } \\
\hline A0A1D6MQM6 & Carbohydrate transporter/sugar porter/transporter & 1.8 & - & - & - \\
\hline B6TCP1 & Carbohydrate transporter/sugar porter/transporter & 1.46 & - & - & - \\
\hline A0A1D6MV11 & Sucrose transporter 4 & - & - & 1.31 & - \\
\hline A0A1D6IFG4 & Sugar carrier protein $C$ & 1.35 & - & - & - \\
\hline B6TEX4 & Sugar transport protein 5 & 0.78 & - & - & - \\
\hline A0A1D6MLZ7 & Plastidic glucose transporter 4 & - & - & 1.25 & - \\
\hline A0A1D6IWW8 & Putative polyol transporter 1 & 1.51 & - & - & - \\
\hline A0A1D6IHY2 & Putative polyol transporter 1 & - & - & 1.45 & - \\
\hline A0A1D61HX5 & Putative polyol transporter 1 & - & - & 1.38 & - \\
\hline A0A1D6GE23 & D-Xylose-proton symporter-like 3 chloroplastic & - & - & 1.37 & - \\
\hline \multicolumn{6}{|l|}{ Cation transporters } \\
\hline A0A096PXB4 & Vacuolar cation/proton exchanger 3 & 2.61 & - & - & - \\
\hline B4FUC4 & Plasma membrane-associated cation-binding protein 1 & 1.56 & - & 1.77 & 1.52 \\
\hline A0A1D6HHV5 & Cation/H(+) antiporter 1 & 1.45 & - & - & - \\
\hline $\mathrm{COPHC} 1$ & Chloride channel protein & 1.42 & - & 1.28 & - \\
\hline A0A1D6FLY1 & Calcium permeable stress-gated cation channel 1 & - & - & 1.21 & - \\
\hline A0A1D6N218 & Potassium transporter 3 & - & - & 1.42 & - \\
\hline W5UB74 & Potassium transporter & - & - & 1.26 & - \\
\hline A0A1D6DSW6 & $\mathrm{K}(+)$ efflux antiporter 2 chloroplastic & 1.68 & - & - & - \\
\hline A0A1D6JIE4 & $\mathrm{K}(+)$ efflux antiporter 2 chloroplastic & 1.32 & - & - & - \\
\hline B6T7A1 & Voltage-gated potassium channel beta subunit & - & - & 0.8 & - \\
\hline A0A1D6KAA6 & Protein NRT1/PTR family 8.3 & - & - & 1.35 & - \\
\hline A0A1D6N629 & Protein NRT1/PTR family 5.10 & - & - & 0.68 & - \\
\hline \multicolumn{6}{|l|}{$A B C$ transporters } \\
\hline A0A1D6NEQ4 & ABC transporter B family member 9 & - & - & 2.34 & - \\
\hline A0A1D6G2R7 & ABC transporter B family member 9 & - & - & 1.55 & - \\
\hline A0A1D6MRC7 & ABC transporter B family member 21 & 1.38 & - & - & - \\
\hline A0A1D6J0E8 & ABC transporter B family member 19 & - & - & 1.83 & - \\
\hline A0A1D6J8P3 & ABC transporter B family member 15 & - & - & 1.67 & - \\
\hline A0A1D6FYX8 & ABC transporter $\mathrm{G}$ family member 40 & - & - & 1.79 & - \\
\hline A0A1D6Q0P9 & ABC transporter A family member 7 & - & - & 1.68 & - \\
\hline A0A1D6Q0P8 & ABC transporter A family member 7 & & - & 1.3 & - \\
\hline A0A1D6E1K8 & ABC transporter $C$ family member 9 & - & - & 1.51 & - \\
\hline A0A1D6FF20 & ABC transporter $C$ family member 3 & - & - & 1.49 & - \\
\hline
\end{tabular}


Table 3 Differentially expressed transporters of QXN233 identified under LP or HP condition compared with the normal condition by the proteomic analysis (Ratio $\mid 0$ Pi or $3 \mathrm{Pi} /$ Control| $>1.2$ and $P<0.05$ ) (Continued)

\begin{tabular}{|c|c|c|c|c|c|}
\hline Accession number & Protein description & $\mathrm{L}-(\mathrm{OPi} /$ Control) & L-(3Pi/Control) & $\mathrm{R}-(\mathrm{OPi} /$ Control) & R-(3Pi/Control) \\
\hline A0A1D6EEY6 & ABC transporter $C$ family member 4 & - & - & 1.47 & - \\
\hline K7VCA6 & ABC transporter $C$ family member 4 & - & - & 1.43 & - \\
\hline A0A1D6J4B3 & $\mathrm{ABC}$ transporter $\mathrm{C}$ family member 4 & - & - & 1.37 & - \\
\hline \multicolumn{6}{|c|}{ Amino acid transporters } \\
\hline A0A1D6KGL1 & Cationic amino acid transporter 4 vacuolar & - & - & 1.45 & - \\
\hline A0A1D6KGL3 & Cationic amino acid transporter 4 vacuolar & 1.36 & - & - & - \\
\hline A0A097ETZ6 & Urea transporter & - & - & 0.82 & - \\
\hline B4FYF5 & Lysine histidine transporter 2 & - & - & 0.76 & - \\
\hline \multicolumn{6}{|l|}{ Vesicle transporters } \\
\hline A0A1D6G304 & Vesicle transport v-SNARE 12 & - & - & 1.44 & 1.27 \\
\hline B4FFY7 & Endoplasmic reticulum vesicle transporter protein & - & - & 0.81 & - \\
\hline A0A1D6E9B4 & Endoplasmic reticulum vesicle transporter protein & 1.28 & - & - & - \\
\hline \multicolumn{6}{|l|}{ Metal transporters } \\
\hline A0A1D6PHW0 & Metal transporter Nramp3 & - & - & 1.35 & - \\
\hline A0A1D6M2W3 & Heavy metal transport/detoxification superfamily & 0.79 & - & - & - \\
\hline \multicolumn{6}{|l|}{ Other transporters } \\
\hline K7UFL6 & Putative glycerol-3-phosphate transporter 1 & - & - & 2.15 & - \\
\hline A0A1D6JAP3 & Putative sphingolipid transporter spinster homolog 2 & - & - & 1.25 & - \\
\hline A0A1D6KXB5 & Organic cation/carnitine transporter 7 & 1.45 & - & 1.92 & - \\
\hline A0A096TR23 & Molybdate transporter 2 & 2.08 & - & 1.54 & - \\
\hline E3UJZ2 & Putative metal-nicotianamine transporter YSL7 & 1.27 & - & - & - \\
\hline A0A1D6PKM7 & Boron transporter 4 & 0.77 & - & - & - \\
\hline
\end{tabular}

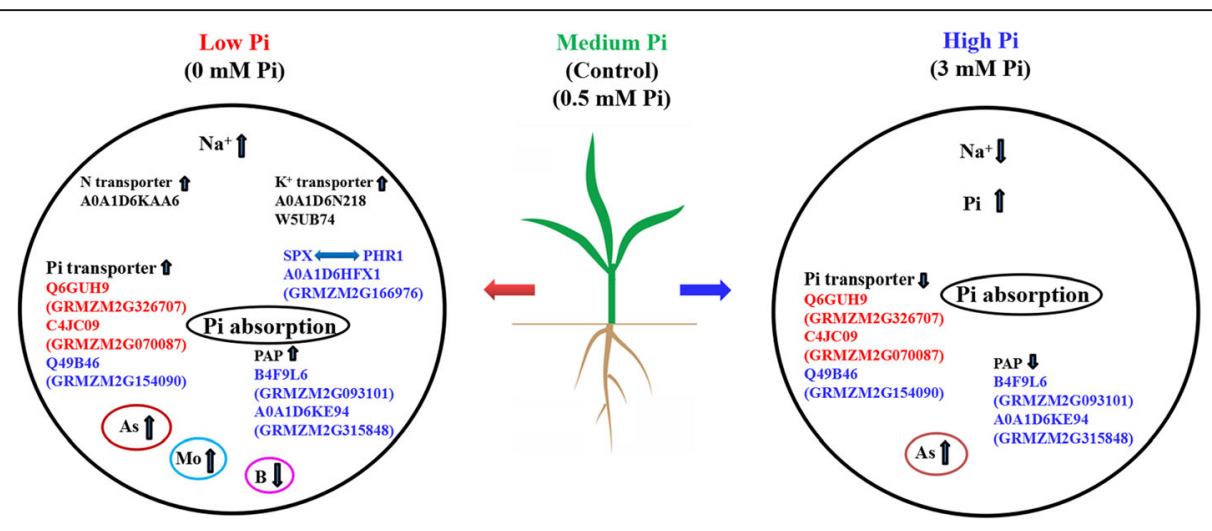

Fig. 11 Schematic representation of the regulated mechanism of QXN233 in response to long-term exposure to LP and HP conditions. Pi transporter proteins Q6GUH9, Q49B46, and C4JC09 were upregulated under LP condition but downregulated under HP condition. Some other relevant proteins including Pi-responsive proteins (B6SYB8 and A0A1D6QB24), SPX domain protein (A0A1D6HFX1) and two $\mathrm{K}^{+}$transporters (A0A1D6N218 and W5UB74), and nitrate transporters (A0A1D6KAA6 and A0A1D6N629), were uniquely altered, together contributing to Pi absorption and homeostasis under different Pi conditions. A negative relationship between $\mathrm{Na}^{+}$and Pi existed in plants under HP condition. Some other relevant proteins, including PAPs (B6SYB8 and A0A1D6QB24), SPX domain protein (A0A1D6HFX1) related to the regulation of PHR1 and two K $\mathrm{K}^{+}$transporters (A0A1D6N218 and W5UB74), and nitrate transporters (A0A1D6KAA6), were uniquely altered, together contributing to Pi absorption and homeostasis under different Pi conditions. In addition, it was shown that Pi had interactions with the micronutrients of As, Mo and B 
shoots under LP condition, possibly indicating low salt tolerance. Importantly, in contrast to an increased $\mathrm{Na}^{+}$ content, a decreased Pi content was found under LP condition, while a reverse $\mathrm{Na}^{+}-\mathrm{Pi}$ content pattern existed under HP condition (Fig. 3a, c), showing a negative relationship between $\mathrm{Na}^{+}$and Pi. Moreover, a high $\mathrm{Na}^{+}$accumulation and $\mathrm{Na}^{+} / \mathrm{K}^{+}$ratio appeared in roots under LP condition, although no significant difference in Pi content was observed (Fig. 3a, d). Thus, high $\mathrm{Na}^{+}$in shoots might have been attributed to high $\mathrm{Na}^{+}$retention in roots under LP condition. Furthermore, a high $\mathrm{Na}^{+}$ efflux in QXN233 root was detected under HP condition by NMT (Fig. 4a), hinting that $\mathrm{Na}^{+}$efflux could be induced by external HP supplementation. Consequently, these results demonstrated a negative regulated relationship between $\mathrm{Na}^{+}$and $\mathrm{Pi}$, and $\mathrm{Na}^{+}$exclusion could be promoted by external HP supplementation. This result can be attributed to the fact that salt tolerance may be improved by sufficient Pi application, which requires further study. If proven in the future, then external HP supplementation may be applied to improve crop.

Using RNA-Seq analysis, we previously detected several key Pi transporters that were elevated in QXN233 under Pi deficiency, such as the Pi transporter genes GRMZM2G112377, GRMZM2G070087 and GRMZM2G326707 were identified to be key genes for maize growth under LP condition [52]. Compared to our previous study, the proteomic analysis revealed that several Pi transport proteins, including Q6GUH9 (GRMZM2G326707), C4JC09 (GRMZM2G070087), and Q49B46 (GRMZM2G154090), were also upregulated under LP condition but downregulated under HP condition in the present study (Fig. 10; Table 2), implying that these proteins, especially for Q6GUH9 and C4JC09, were vital regulators for Pi absorption and transport (Fig. 11). Hence, the overexpression or RNA interference of these Pi transporter proteins was needed to verify their functions and effects on LP tolerance of maize. Moreover, Pi starvation-induced protein (B6SYB8), Pi transporter 2 (A0A1D6QB24), and SPX domain-containing membrane protein (A0A1D6HFX1) were also increased in the leaves or roots under Pi deficiency (Table 3). Previous studies revealed that SPX domain proteins regulate the expression of PHR in Arabidopsis and rice [31-33, 35]; however, no studies have investigated the SPX domain proteins in maize. Here, SPX domain proteins (A0A1D6HFX1) were first identified in maize response to long-term Pi deficiency, and ZmPHR1 was also detected in roots response to LP for $12 \mathrm{~h}$, suggesting that SPX protein participate in regulating the Pi signal pathway in maize (Fig. 11) and need to be further investigated next. Therefore, these proteins can be used as key candidates for gene engineering by the single or combined expression of their encoding genes in breeding tolerant maize in the future.
Finally, some cation transporters were identified and altered under LP or HP condition, especially for nitrate and potassium, indicating that $\mathrm{Pi}$ influenced the uptake of $\mathrm{K}$ and N. Other transporters, including carbohydrate, As, Mo, and $B$ transporters, were observed, thereby implying that Pi had cross-talks with sugar metabolism and As, Mo and $B$ transports. This result is consistent with the findings of previous studies [37, 42-48]. Therefore, Pi has a complex interplay with other nutrients and pathways, which needs to be further verified in the future.

\section{Conclusions}

This study is the first to perform quantitative proteomic investigation to identify DEPs in maize under long-term LP and HP treatments. In-depth analysis of the 185 overlapped DEPs provided new insights into QXN233 responses to different Pi levels. Among them, Q6GUH9, Q49B46 and C4JC09 (phosphate transporters), B4F9L6 and A0A1D6KE94 (purple acid phosphatases), and A0A1D6HFX1 (SPX domain protein) associated with $\mathrm{Pi}$ assimilation and regulation, were increased under LP stress but decreased under HP supplementation, indicating that these DEPs play key roles in Pi homeostasis for maize coping with different Pi levels. These foundings will improve our understanding on how maize seedlings regulate DEPs to respond to different Pi environments. The key DEPs are also candidate proteins that may aid in the selection and breeding of LP-tolerant maize genotype.

\section{Additional file}

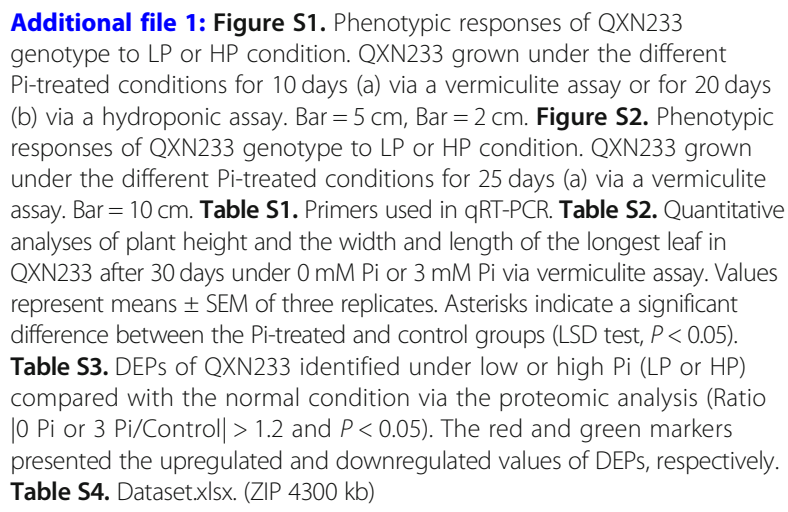

\section{Abbreviations}

ABC transporter: ATP-binding cassette transporter; As: Ascorbate; B: Boron; DEPs: Differently expression proteins; FDR: False discovery rate; GO: Gene Ontology; HCD: Higher-energy collisional dissociation; HP: High Pi; KEGG: Kyoto Encyclopedia of Genes and Genomes; LC-MS/MS: Nano-liquid chromatography-mass spectrometry; LP: Low Pi; MDA: Malondialdehyde; Mo: Molybdate; MYB: Myeloblastosis viral oncogene homolog; NMT: Noninvasive micro-test technology; NPP: Nucleotide pyrophosphatase/ phosphodiesterase; P: Phosphorus; P1BS: PHR1-binding sequence; P5CR: Pyrroline-5-carboxylate reductase; P5CS: Pyrroline-5-carboxylate synthetase; PAP: Purple acid phosphatase; PHO1: Phosphate 1; PHR1: Phosphate starvation response 1; PHT1: Phosphate receptor 1; 
Pi: Inorganic phosphate; qRT-PCR: Quantitative real-time polymerase chain reaction; SOD: Superoxide dismutase; SPX: SYG1, Pho81 and XPR1; TFs: Transcription factors; TMT: Tandem mass tag; TPS1: Trehalose-6phosphate synthase

\section{Acknowledgments}

Not applicable.

\section{Funding}

This work was supported by the grants from Natural Science Foundation of Shandong Province (grant no. ZR2017BC021), the Special Fund for Agro-scientific Research in the Public Interest (grant no. 201503130), the National Natural Science Foundation of China (grant no.31301271), the major agricultural innovation project of Shandong Province (grant no. 2017cxgx0311).

\section{Availability of data and materials}

Processed data included within Additional file 1: Tables S1-S4 and Figures S1-S2.

\section{Authors' contributions}

YS performed the experiments, data analysis and composed the draft of the manuscript. CM and XL contributed reagents/materials. YS and XL conceived and supervised the experimental work. All authors have read and approved the final manuscript.

\section{Ethics approval and consent to participate}

Not applicable.

\section{Consent for publication}

Not applicable.

\section{Competing interests}

The authors declare that they have no conflicts of interest in this work.

\section{Publisher's Note}

Springer Nature remains neutral with regard to jurisdictional claims in published maps and institutional affiliations.

\section{Author details}

${ }^{1}$ Maize Research Institute, Shandong Academy of Agricultural Sciences/ National Engineering Laboratory of Wheat and Maize/Key Laboratory of Biology and Genetic Improvement of Maize in Northern Yellow-huai River Plain, Ministry of Agriculture, Jinan 250100, China. ${ }^{2}$ College of Life Sciences, Shandong Normal University, Jinan 250000, Shandong, China.

\section{Received: 7 May 2018 Accepted: 8 November 2018}

\section{Published online: 20 November 2018}

\section{References}

1. Puga MI, Rojas-Triana M, de Lorenzo L, Leyva A, Rubio V, Paz-Ares J. Novel signals in the regulation of Pi starvation responses in plants: facts and promises. Curr Opin Plant Biol. 2017;39:40-9.

2. Ham BK, Chen J, Yan Y, Lucas WJ. Insights into plant phosphate sensing and signaling. Curr Opin Biotechnol. 2018:49:1-9.

3. Lynch JP. Root phenes for enhanced soil exploration and phosphorus acquisition: Tools for future crops. Plant Physiol. 2011;156:1041-9.

4. Heuer S, Gaxiola R, Schilling R, Herrera-Estrella L, López-Arredondo D, Wissuwa $\mathrm{M}$, et al. Improving phosphorus use efficiency: a complex trait with emerging opportunities. Plant J. 2017;90(5):868-85.

5. López-Arredondo DL, Leyva-González MA, González-Morales SI, López-Bucio J, Herrera-Estrella L. Phosphate nutrition: improving low-phosphate tolerance in crops. Annu Rev Plant Biol. 2014;65:95-123.

6. Wang D, Lv S, Jiang P, Li Y. Roles, regulation, and agricultural application of plant phosphate transporters. Front Plant Sci. 2017;18(8):817.

7. Nakamura Y. Phosphate starvation and membrane lipid remodeling in seed plants. Prog Lipid Res. 2013;52:43-50.

8. Javot H, Pumplin N, Harrison MJ. Phosphate in the arbuscular mycorrhizal symbiosis: transport properties and regulatory roles. Plant Cell Environ. 2007; 30:310-22.

9. Baker A, Ceasar SA, Palmer AJ, Paterson JB, Qi W, Muench SP, et al. Replace, reuse, recycle: improving the sustainable use of phosphorus by plants. J Exp Bot. 2015;66(12):3523-40.
10. Gu M, Chen A, Sun S, Xu G. Complex regulation of plant phosphate transporters and the gap between molecular mechanisms and practical application: what is missing? Mol Plant. 2016;9(3):396-416.

11. Jiang H, Zhang J, Han Z, Yang J, Ge C, Wu Q. Revealing new insights into different phosphorus-starving responses between two maize (Zea mays) inbred lines by transcriptomic and proteomic studies. Sci Rep. 2017;7:44294.

12. Zhang L, Li J, Rong T, Gao S, Wu F, Xu J, et al. Large-scale evaluation of maize germplasm for low-phosphorus tolerance. PLoS ONE. 2015;10:e0124212.

13. González-Muñoz E, Avendaño-Vázquez AO, Montes RA, de Folter S, AndrésHernández L, Abreu-Goodger C, et al. The maize (Zea mays ssp. mays var. B73) genome encodes 33 members of the purple acid phosphatase family. Front Plant Sci. 2015;6:341.

14. Wang Y, Ribot C, Rezzonico E, Poirier Y. Structure and expression profile of the Arabidopsis PHO1 gene family indicates a broad role in inorganic phosphate homeostasis. Plant Physiol. 2004;135:400-11.

15. Zhou Z, Wang Z, Lv Q, Shi J, Zhong Y, Wu P, et al. SPX proteins regulate Pi homeostasis and signaling in different subcellular level. Plant Signal Behav. 2015;10:e1061163.

16. Młodzińska E, Zboińska M. Phosphate uptake and allocation-a closer look at. Arabidopsis thaliana L. and Oryza sativa L. Front Plant Sci. 2016;7:1198.

17. Wang F, Deng M, Xu J, Zhu X, Mao C. Molecular mechanisms of phosphate transport and signaling in higher plants. Semin Cell Dev Biol. 2018;74:114-22.

18. Ham BK, Chen J, Yan Y, Lucas WJ. Insights into plant phosphate sensing and signaling. Curr Opin Biotechnol. 2018;49:1-9.

19. Poirier Y, Bucher M. Phosphate transport and homeostasis in Arabidopsis. In: Arabidopsis Book, vol. 1; 2002. p. e0024.

20. López-Arredondo DL, Leyva-González MA, González-Morales SI, LópezBucio J, Herrera-Estrella L. Phosphate nutrition: improving low-phosphate tolerance in crops. Annu Rev Plant Physiol. 2014;65:95-123.

21. Liu J, Yang L, Luan M, Wang Y, Zhang C, Zhang B, et al. A vacuolar phosphate transporter essential for phosphate homeostasis in Arabidopsis. Proc Natl Acad Sci U S A. 2015;112:6571-8.

22. Secco D, Baumann A, Poirier Y. Characterization of the rice PHO1 gene family reveals a key role for $\mathrm{OsPHO1;2}$ in phosphate homeostasis and the evolution of a distinct clade in dicotyledons. Plant Physiol. 2010;152:1693-704.

23. Nagy R, Vasconcelos MJV, Zhao S, McElver J, Bruce W, Amrhein N, et al. Differential Regulation of Five Pht1 Phosphate Transporters from Maize (Zea mays L.). Plant Biol. 2006;8:186-97.

24. Liu F, Xu Y, Jiang H, Jiang C, Du Y, Gong C, et al. Systematic identification, evolution and expression analysis of the Zea mays PHT1 gene family reveals several new members involved in root colonization by arbuscular mycorrhizal fungi. Int J Mol Sci. 2016;17(6):930.

25. Mlodzińska E, Zboińska M. Phosphate uptake and allocation-a closer look at Arabidopsis thaliana L. and Oryza sativa L. Front Plant Sci. 2016;7:1198.

26. Rausch C, Bucher M. Molecular mechanisms of phosphate transport in plants. Planta. 2002;21:23-37.

27. Rubio V, Linhares F, Solano R, Martin AC, Iglesias J, Leyva A, et al. A conserved MYB transcription factor involved in phosphate starvation signaling both in vascular plants and in unicellular algae. Genes Dev. 2001;15(16):2122-33.

28. Schünmann PH, Richardson AE, Vickers CE, Delhaize E. Promoter analysis of the barley Pht 1; 1 phosphate transporter gene identifies regions controlling root expression and responsiveness to phosphate deprivation. Plant Physiol. 2004;136:4205-14.

29. Shin H, Shin HS, Chen R, Harrison MJ. Loss of At4 function impacts phosphate distribution between the roots and the shoots during phosphate starvation. Plant J. 2006:45:712-26.

30. Chen J, Liu Y, Ni J, Wang Y, Bai Y, Shi J, et al. OsPHF1 regulates the plasma membrane localization of low- and high-affinity inorganic phosphate transporters and determines inorganic phosphate uptake and translocation in rice. Plant Physiol. 2011;157:269-78.

31. Secco D, Wang C, Arpat BA, Wang Z, Poirier Y, Tyerman SD, et al. The emerging importance of the SPX domain-containing proteins in phosphate homeostasis. New Phytol. 2012;193(4):842-51.

32. Puga MI, Mateos I, Charukesi R, Wang Z, Franco-Zorrilla JM, de Lorenzo L, et al. SPX1 is a phosphate-dependent inhibitor of PHOSPHATE STARVATION RESPONSE 1 in Arabidopsis. PNAS. 2014;111(41):14947-52.

33. Wang Z, Ruan W, Shi J, Zhang L, Xiang D, Yang C, et al. Rice SPX1 and SPX2 inhibit phosphate starvation responses through interacting with PHR2 in a phosphate-dependent manner. PNAS. 2014;111:14953-8.

34. Duan K, Yi K, Dang L, Huang H, Wu W, Wu P. Characterization of a sub-family of Arabidopsis genes with the SPX domain reveals their diverse functions in plant tolerance to phosphorus starvation. Plant J. 2008;54:965-75. 
35. LV Q, Zhong Y, Wang Y, Wang Z, Zhang L, Shi J, et al. SPX4 negatively regulates phosphate signaling and homeostasis through its interaction with PHR2 in rice. Plant Cell. 2014;26:1586-97.

36. Wild R, Gerasimaite R, Jung JY, Truffault V, Pavlovic I, Schmidt A, et al. Control of eukaryotic phosphate homeostasis by inositol polyphosphate sensor domains. Science. 2016;352:986-90.

37. Kant $\mathrm{S}$, Peng M, Rothstein SJ. Genetic regulation by NLA and microRNA827 for maintaining nitrate-dependent phosphate homeostasis in Arabidopsis. PLoS Genetics. 2011;7:e1002021.

38. Rouached H, Secco D, Arpat B, Poirier Y. The transcription factor PHR1 plays a key role in the regulation of sulfate shoot-to-root flux upon phosphate starvation in Arabidopsis. BMC Plant Biol. 2011;11:19.

39. Khan GA, Bouraine S, Wege S, Li Y, de Carbonnel M, Berthomieu P, et al. Coordination between zinc and phosphate homeostasis involves the transcription factor PHR1, the phosphate exporter PHO1, and its homologue PHO1;H3 in Arabidopsis. J Exp Bot. 2014;65:871-84.

40. Bournier M, Tissot N, Mari S, Boucherez J, Lacombe E, Briat JF, et al. Arabidopsis ferritin 1 (AtFer1) gene regulation by the phosphate starvation response 1 (AtPHR1) transcription factor reveals a direct molecular link between iron and phosphate homeostasis. J Biol Chem. 2013;288:22670-80.

41. Hammond JP, White PJ. Sucrose transport in the phloem: integrating root responses to phosphorus starvation. J Exp Bot. 2008:59:93-109.

42. Rubio V, Bustos R, Irigoyen ML, Cardona-López X, Rojas-Triana M, Paz-Ares J. Plant hormones and nutrient signaling. Plant Mol Biol. 2009;69:361-73.

43. Briat JF, Rouached H, Tissot N, Gaymard F, Dubos C. Integration of P, S, Fe, and $\mathrm{Zn}$ nutrition signals in Arabidopsis thaliana: potential involvement of PHOSPHATE STARVATION RESPONSE 1 (PHR1). Front Plant Sci. 2015;6:290.

44. Tang X, Lim MP, MB MB. Arsenic uptake by arugula (Eruca vesicaria, L.) cultivars as affected by phosphate availability. Chemosphere. 2018;195:559-66.

45. Teng W, Kang Y, Hou W, Hu H, Luo W, Wei J, et al. Phosphorus application reduces aluminum toxicity in two Eucalyptus clones by increasing its accumulation in roots and decreasing its content in leaves. PLoS One. 2018; 13(1):e0190900.

46. Zhang R, Li C, Fu K, Li C, Li C. Phosphorus alters starch morphology and gene expression related to starch biosynthesis and degradation in wheat grain. Front Plant Sci. 2018;8:2252.

47. PAA F, Tiecher T, Tiecher TL, Rangel WM, CRFS S, Deuner S, et al. Effects of Rhizophagus clarus and $\mathrm{P}$ availability in the tolerance and physiological response of Mucuna cinereum to copper. Plant Physiol Biochem. 2018;122:46-56.

48. Del-Saz NF, Romero-Munar A, Cawthray GR, Palma F, Aroca R, Baraza E, et al. Phosphorus concentration coordinates a respiratory bypass, synthesis and exudation of citrate, and the expression of high-affinity phosphorus transporters in Solanum lycopersicum. Plant Cell Environ. 2018;41:865-75.

49. Calderon-Vazquez C, Ibarra-Laclette E, Caballero-Perez J, Herrera-Estrella L. Transcript profiling of Zea mays roots reveals gene responses to phosphate deficiency at the plant- and species-specific levels. J Exp Bot. 2008;59:2479-97.

50. Lin HJ, Gao J, Zhang ZM, Shen YO, Lan H, Liu L, et al. Transcriptional responses of maize seedling root to phosphorus starvation. Mol Biol Rep. 2013;40(9):5359-79.

51. Ganie AH, Ahmad A, Pandey R, Aref IM, Yousuf PY, Ahmad S, et al. Metabolite profiling of low-P tolerant and Low-P sensitive maize genotypes under phosphorus stanvation and restoration conditions. PLoS One. 2015;10:e0129520.

52. Sun Y, Mu C, Chen Y, Kong X, Xu Y, Zheng H, Zhang H, Wang Q, Xue Y, Li Z, Ding Z, Liu X. Comparative transcript profiling of maize inbreds in response to long-term phosphorus deficiency stress. Plant Physiol Biochem. 2016;109:467-81.

53. Sun Y, Kong X, Li C, Liu Y, Ding Z. Potassium retention under salt stress is associated with natural variation in salinity tolerance among Arabidopsis accessions. PLoS One. 2015;10:e0124032.

54. Wiśniewski JR, Zougman A, Nagaraj N, Mann M. Universal sample preparation method for proteome analysis. Nat Methods. 2009;6:359-62.

55. Al-Karaki GN. Barley response to salt stress at varied levels of phosphorus. J Plant Nutr. 1997;20:1635-43.

56. Phang TH, Shao G, Liao H, Yan X, Lam HM. High external phosphate (Pi) increases sodium ion uptake and reduces salt tolerance of 'Pi-tolerant' soybean. Physiol Plantarum. 2009;135:412-25.

\section{Ready to submit your research? Choose BMC and benefit from}

- fast, convenient online submission

- thorough peer review by experienced researchers in your field

- rapid publication on acceptance

- support for research data, including large and complex data types

- gold Open Access which fosters wider collaboration and increased citations

- maximum visibility for your research: over $100 \mathrm{M}$ website views per year

At BMC, research is always in progress.

Learn more biomedcentral.com/submissions 